\title{
Why Do Individuals Exhibit Investment Biases?*
}

\author{
Henrik Cronqvist and Stephan Siegel ${ }^{\dagger}$ \\ First draft: September 19, 2011 \\ This draft: October 12, 2012
}

\begin{abstract}
For a long list of investment "biases," e.g., home bias, loss aversion, and performance chasing, we find that genetic differences explain up to $45 \%$ of the variation across individual investors. The genetic factors that influence investment biases are also found to affect behaviors in other, non-investment, domains. This evidence is consistent with a view that investment biases are manifestations of innate and evolutionary ancient features of human behavior. The environment an investor experiences also affects investment biases, either directly or as a moderator of genetic predispositions. For example, we find that work-related experience with finance seems to reduce genetic predispositions to investment biases, while general education does not. Finally, even genetically identical investors, who grow up in the same family environment, often differ substantially in their investment behaviors due to individual-specific experiences or events.
\end{abstract}

\footnotetext{
${ }^{*}$ We are thankful for comments from seminar participants at the Arizona State University Sonoran Winter Conference, Australian National University, China Europe International Business School, China International Conference in Finance, 14th Congress of the International Society of Twin Studies, Copenhagen Business School, Erasmus University, Florida State University SunTrust Conference, 1st Linde Institute Conference at Caltech, Maastricht University, Nanyang Technological University, Singapore Management University, Swedish Institute for Financial Research (SIFR), Tilburg University, University of Michigan-Dearborn, University of New South Wales, University of Sydney, University of Technology Sydney, Washington University in St. Louis, and discussions with Julie Agnew, Brad Barber, Alon Brav, David Hirshleifer, Zoran Ivković, Markku Kaustia, Matti Keloharju, Samuli Knüpfer, Lisa Kramer, Andy Lo, Annamaria Lusardi, Oliver Spalt, Per Strömberg, Mike Weisbach, Frank Yu, and Paul Zak. We acknowledge generous research funding from the 2011-12 Faculty Research Award of the Betty F. Elliott Initiative for Academic Excellence, College of Business, The University of Michigan-Dearborn. We thank Florian Münkel, Lucas Perin, and Lew Thorson for excellent research assistance, Jack Goldberg (Twin Registry at University of Washington) and Nancy Segal (Twin Studies Center at California State University, Fullerton) for advice related to twins studies, and Kara Ralston for editorial assistance. This project was pursued in part when Cronqvist was Olof Stenhammar Visiting Professor at SIFR, which he thanks for its support, and while Siegel was visiting W. P. Carey School of Business at Arizona State University, which he thanks for their hospitality. Statistics Sweden and the Swedish Twin Registry (STR) provided the data for this study. STR is supported by grants from the Swedish Research Council, the Ministry of Higher Education, AstraZeneca, and the National Institute of Health (grants AG08724, DK066134, and CA085739). Any errors or omissions are our own.

${ }^{\dagger}$ Cronqvist: McMahon Family Chair in Corporate Finance, George R. Roberts Fellow, and Associate Professor of Financial Economics, Claremont McKenna College, Robert Day School of Economics and Finance (hcronqvist@cmc.edu); Siegel: Assistant Professor of Finance and Business Economics, Michael G. Foster School of Business; University of Washington (ss1110@uw.edu).
} 


\section{Introduction}

The list of investment "biases" that individual investors exhibit is long. They lack diversification and have a preference for familiar investments (French and Poterba (1991) and Huberman (2001)), trade too much (Odean (1999)), are reluctant to realize their losses (Odean (1998) and Dhar and Zhu (2006)), extrapolate recent superior returns (Benartzi (2001)), and have a preference for skewness and lottery-type investments (Kumar (2009)). These behaviors have previously been partially attributed to mechanisms rooted in psychology research: Ambiguity aversion and familiarity for lack of diversification (Ellsberg (1961) and Heath and Tversky (1991)), overconfidence for excessive trading (Griffin and Tversky (1992)), loss aversion and mental accounting for the reluctance to realize losses (Kahneman and Tversky (1979) and Thaler (1985)), representativeness and the hot hands fallacy for excessive extrapolation of past returns (Tversky and Kahneman (1974)), and cumulative prospect theory for skewness preferences (Tversky and Kahneman (1992)). ${ }^{1}$

While the previously referenced studies have shown that individual investors, on average, exhibit these investment biases, little research has been devoted to understanding why investors exhibit these behaviors or why some investors are more biased than others. Are investors born with certain predispositions that manifest themselves as investment biases? Or do investors exhibit biases as a result of parenting or individual-specific experiences or events? The origins of investment biases have potentially important implications for the extent to which education and market incentives may be expected to reduce investment biases and also for the design of public policy.

We use standard empirical methodology adopted from quantitative behavioral genetics research (see Neale and Maes (2004) for an overview), which has recently been used also in finance research (e.g., Barnea, Cronqvist, and Siegel (2010) and Cesarini et al. (2010)). Our data set from the world's largest twin registry, the Swedish Twin Registry (STR), matched with detailed data on the twins' investment behaviors, enables us to decompose differences across individuals into genetic versus environmental components. This decomposition is based on an intuitive insight: Identical twins

\footnotetext{
${ }^{1}$ Throughout the paper, we will refer to these behaviors as "biases" because they constitute non-standard preferences and beliefs from the perspective of standard models used in financial economics. It is beyond the scope of this paper to provide estimates of the potential welfare losses attributed to any of these behaviors. Some of the referenced papers provide such estimates.
} 
share $100 \%$ of their genes, while the average proportion of shared genes is only $50 \%$ for fraternal twins. If identical twins exhibit more similarity with respect to these investment behaviors than do fraternal twins, then there is evidence that these behaviors are influenced, at least in part, by genetic factors.

We can summarize our results as follows. First, for a long list of investment biases, we find that genetic differences explain up to $45 \%$ of the variation across individual investors. Consistent with a view that investment biases are manifestations of innate and evolutionary ancient features of human behavior, we find that the genetic factors that influence investment biases also affect behaviors in other, non-investment, domains. For example, the correlation between a preference for familiar stocks and familiarity preferences in other domains is due to shared genetic influences. While our results are consistent with several behavioral genetic studies that have shown significant heritability of human behavior, they provide the first direct evidence from real-world, non-experimental data that persistent investment behaviors are to a significant extent determined by genetic endowments. Such evidence provides support for evolutionary arguments that behaviors which manifest themselves as investment biases in today's financial markets have survived because they were advantageous in evolutionary ancient times (e.g., Rayo and Becker (2007) and Brennan and Lo (2011)).

The relative importance of genetic relative to environmental factors is found to vary across different investors. Most importantly, among investors with work-related experience with finance, we find a significant reduction of the relative amount of genetic variation, which is consistent with the notion that practical experience in finance moderates genetic predispositions. We cannot rule out, though, that the selection of profession reduces the relevant genetic variation in this sub-sample. Controlling for selection, we also investigate the role of general education, measured as years of educations, in moderating the relative importance of genetic factors. We find that general education does not reduce the relative importance of genetic factors in explaining investment biases.

Finally, we find that even genetically identical investors who grew up in the same family environment differ substantially in terms of their investment behaviors. Individual-specific environments, experiences, or events must therefore play an important role in shaping individuals' investment choices. Examining differences between investment biases of genetically identical investors, we show 
how genetically informed data, such as twin data used in this study, can be used to better assess the causal impact of individual-specific factors, such as education.

The paper is organized as follows. Section II reviews related research. Section III describes our data sources, reports summary statistics, and defines our measures of investment biases. Section IV describes our empirical methodology. Sections V and VI report our results and robustness checks. Section VII concludes.

\section{The Origins of Investment Biases}

\section{A Genetic Origins}

\section{A.1 Models of the Evolution of Behavior}

The literature on the evolution of behavior is large, and includes disciplines such as biology, evolutionary psychology, and economics. It is beyond the scope of this paper to review this literature. For extensive reviews, we refer to Robson (2001), Rayo and Becker (2007), Brennan and Lo (2011), and the examples and references therein. Underlying this literature is the assumption that some of the variation in behavior is due to genetic differences. Over time, those behaviors that confer greater "fitness", i.e. reproductive success, become more common in the population. The outcome of this natural selection process, of course, depends on the environment as different behaviors will have more or less reproductive success in different environments.

Behaviors and psychological mechanisms that manifest themselves as investment biases in modern financial markets, could be widespread today, because they were associated with a reproductive advantage relative to alternative behaviors over the course of human development. That is, evolution might have selected behaviors that were fitness maximizing in evolutionary ancient times, but may not be optimal in all relevant domains today (e.g., Waldman (1994) and Rayo and Becker (2007)). Rayo and Becker (2007), for example, argue (p. 304):

"[W] hen talking about fitness-maximizing [utility] functions, we refer to functions that optimized genetic multiplication during hunter-gatherer times (before agriculture and animal domestication were developed). In modern times, on the other hand, we presumably share most of the innate characteristics of our hunter-gatherer ancestors. But since the technological landscape has 
changed so rapidly since the rise of agriculture, our [utility] functions need no longer optimally promote the present multiplication of our genes."

For example, in a hunter-gatherer society it may generally have been harmful for humans to explore or invest in the unfamiliar, which may explain a strong preference for investing in the familiar even today (e.g., Benartzi (2001) and Huberman (2001)). Johnson and Fowler (2011) show in a formal model that for a wide range of settings overconfidence, essentially an error of judgement with respect to one's qualities and capabilities, can lead to higher "net-payoffs" in competition for resources and might therefore have been favored by evolution. As a consequence, individual investors today might "suffer" from overconfidence in their trading decisions as their behavior is to some extent shaped by genetic endowments that they share with their ancient ancestors. ${ }^{2}$ Brennan and Lo (2011) and McDermott, Fowler, and Smirnov (2008) provide similar arguments for the evolution of loss aversion and prospect theory preferences.

In general, different behaviors can survive and exist in a population as long as they lead to similar reproductive success. For example, if most individuals have a preference for the familiar, the benefit of exploring the unfamiliar might be sufficiently high to compensate for the additional risk. Alternatively, as Brennan and Lo (2011) point out, heterogeneity in behavior could also be due to systematic environmental risks:

"If environmental risks are systematic, survival depends on the population diversifying its behavior so that some fraction will survive to reproduce no matter what the environment is like. In such cases, it may seem as if certain individuals are acting irrationally since they may not be acting optimally for a given environment. But such heterogeneous behavior is, in fact, optimal from the perspective of the population."

In summary, evolutionary models of behavior imply that variation of behavior across individuals is partly due to genetic differences between those individuals. Behavioral biases can survive and become widespread due to the reproductive advantage they have conferred over the course of human evolution.

\footnotetext{
${ }^{2}$ Interestingly, Hirshleifer and Luo (2001) argue that even in today's financial markets overconfident investors can do better than rational investors as they exploit mispricing more aggressively.
} 


\section{A.2 Empirical Evidence}

Table 1 reviews research that links investment biases to psychological mechanisms, and then lists twin and gene candidate studies that link these mechanisms to genetic variation across individuals.

Diversification and Home Bias. Investors often diversify their portfolios less than is recommended by standard models. For example, they overweight stocks from their home market (e.g., French and Poterba (1991)). This home bias has not been easy to explain (e.g., Lewis (1999)). Ambiguity aversion and familiarity (e.g., Heath and Tversky (1991) and Fox and Tversky (1995)) is an alternative approach to explain lack of diversification. The recent gene association study by Chew et al. (2011) identifies several specific genes that affect ambiguity aversion and familiarity.

Turnover. One important stylized facts about individual investors is that they often trade too much (e.g., Odean (1999), Barber and Odean (2000), and Barber, Lee, Liu, and Odean (2009)). Excessive trading has been found to be related to individual characteristics that are partly genetic, such as overconfidence and sensation seeking (e.g., Barber and Odean (2001) and Grinblatt and Keloharju (2009)). Twin studies have documented that both overconfidence and sensation-seeking are partially genetic (Cesarini et al. (2009) and Fulker et al. (1980)). More recent research links sensation seeking to specific genes (Derringer et al. (2010)).

Disposition Effect. Shefrin and Statman (1985) argue that a combination of mental accounting (Thaler, 1985) and prospect theory preferences similar to those in Kahneman and Tversky (1979) makes investors more likely to sell stocks with a gain than with a loss. The recent gene association study by Zhong et al. (2009) identifies the specific genes that affect the concavity and convexity of the prospect theory value function in the gain and loss domains. Furthermore, loss aversion has been found also in animals that are genetically close to humans. Chen, Lakshminarayanan, and Santos (2006) show that capuchin monkeys, which lack experience with markets and finance, exhibit loss aversion: "[L]oss aversion is an innate and evolutionarily ancient feature of human preferences, a function of decision-making systems that evolved before the common ancestors of capuchins and humans diverged" (Chen et al. (2006), p. 520). Finally, Harbaugh, Krause, and Vesterlund (2001) find evidence of loss aversion in children as young as five, and there is no evidence that the behavior disappears significantly with age, at least not through college age. This result also suggests that loss 
aversion is genetic, assuming that these children do not learn such behavior before age five. Twin studies have also documented that loss aversion is partially genetic (e.g., Cesarini et al. (2012))

Performance Chasing. Individual investors often extrapolate recent good stock or fund performance even when it shows little to no persistence (e.g., Patel, Zeckhauser, and Hendricks (1991) and Benartzi (2001)). In their work on representativeness, Tversky and Kahneman (1974) find that people expect that a sequence of outcomes generated by a random process will resemble the essential characteristics of that process even when the sequence is short. Griffin and Tversky (1992) provide an extension documenting that people focus on the strength or extremeness of the evidence with insufficient regard of its credence, predictability, and weight. In contrast to the other investment biases we study, we are not aware of much existing research that directly links excessive extrapolation to specific genes.

Skewness Preference. Investors often exhibit a preference for positive skewness, i.e., lottery-type investments (e.g., Kumar (2009)). Such behavior is expected if investors make decisions based on cumulative prospect theory (Tversky and Kahneman (1992) and Barberis and Huang (2008)). Twin studies have found that the preference to gamble are partially genetic (e.g., Slutske et al. (2000)). Furthermore, the recent gene association study by Zhong et al. (2009) finds that a specific gene results in a preference for gambles with a small probability of a very large payoff.

\section{B Environmental Origins}

While the evolutionary models of behavioral biases imply that behavioral variation across individuals reflects, to some extent, genetic differences, alternative models of the origin of behavior emphasize environmental factors. For example, in models of "direct vertical socialization" children are born without defined preferences, and they are first exposed to their parents' socialization. If parent-child socialization does not succeed, the child is influenced by a random role model in the population (e.g., teachers, co-workers, etc.). These models have been used to explain parent-child similarity with respect to, e.g., religion (e.g., Bisin and Verdier (2000)), but may extend to the investment domain.

The environment may influence investment biases in other ways than through parenting and upbringing. For example, in the model by Gervais and Odean (2001) individual investors learn to 
be biased by becoming overconfident because of their past idiosyncratic investment successes.

While we are not aware of direct empirical tests of the above models with respect to behavioral biases, a growing empirical literature examines the circumstances and events that may reduce the behavioral biases that investors display. The evidence so far suggests that wealthier, more educated, and generally more sophisticated investors make better financial decisions and exhibit fewer investment biases (e.g., Dhar and Zhu (2006), Kumar (2009), Calvet, Campbell, and Sodini (2009)). The identified characteristics of less biased investors do not exclusively represent environmental effects, but also reflect to varying degrees genetic differences across investors. Separating the two and identifying effective intervention is, of course, important from a policy perspective and an area of active research (e.g. Bhattacharya et al. (2012)).

\section{Data}

\section{A Data Sources}

Our data set is constructed by matching a large number of twins from the Swedish Twin Registry (STR), the world's largest twin registry, with data from individual tax filings and other databases by Statistics Sweden. In Sweden, twins are registered at birth, and the STR collects additional data through in-depth interviews. ${ }^{3}$ Importantly, STR's data provide us with the zygosity of each twin pair: Identical or "monozygotic" (MZ) twins are genetically identical, while fraternal or "dizygotic" (DZ) twins are genetically different, and share on average $50 \%$ of their genes. ${ }^{4}$

Until 2007, taxpayers in Sweden were subject to a wealth tax. Prior to the abolishment of this tax, all Swedish banks, brokerage firms, and other financial institutions were required by law to report to the Swedish Tax Authority information about individuals' portfolios (i.e., stocks, bonds,

\footnotetext{
${ }^{3}$ STR's databases are organized by birth cohort. The Screening Across Lifespan Twin, or "SALT," database contains data on twins born 1886-1958. The Swedish Twin Studies of Adults: Genes and Environment database, or "STAGE," contains data on twins born 1959-1985. In addition to twin pairs, twin identifiers, and zygosity status, the databases contain variables based on STR's telephone interviews (for SALT), completed 1998-2002, and combined telephone interviews and Internet surveys (for STAGE), completed 2005-2006. For further details about STR, we refer to Lichtenstein et al. (2006).

${ }^{4}$ Zygosity is based on questions about intrapair similarities in childhood. One of the questions was: Were you and your twin partner during childhood "as alike as two peas in a pod" or were you "no more alike than siblings in general" with regard to appearance? STR has validated this method with DNA analysis as having 98 percent accuracy on a subsample of twins. For twin pairs for which DNA has been collected, zygosity status is based on DNA analysis.
} 
mutual funds, derivatives, and other securities) held as of December 31 and also all sales transactions during the year.

We have matched the twins with portfolio and sales transaction data between 1999 and 2007, providing us with detailed information on investment behavior. For each individual, our data set contains all securities held at the end of the year (identified by each security's International Security Identification Number (ISIN)), the number of each security held, the dividends received during the year, and the end of the year value. We also have data on which securities were sold over the year, and in the case of stocks, the number of securities sold and the sales price. ${ }^{5}$ Security level data have been collected from several sources, including Bloomberg, Datastream, Morningstar, SIX Telekurs, Standard \& Poor's, and the Swedish Investment Fund Association.

\section{B Sample Selection and Summary Statistics}

We follow prior research on investment biases by analyzing equity investments, i.e., individual stocks as well as equity and mixed mutual funds, with a particular focus on individual stocks. We therefore exclude individuals who do not participate in equity markets. Our empirical methodology also requires that we exclude incomplete pairs of twins.

We have 15,208 adult twin pairs in which each twin has at least one year of non-missing equity investment data. Panel A of Table 2 reports summary statistics for our data set, which includes 30,416 individuals. Opposite-sex twins are the most common (37\%); identical male twins are the least common (13\%). The distribution in the table is consistent with what would be expected from large samples of twins (e.g., Bortolus et al. (1999)).

Table 2 Panel B reports summary statistics separately for identical and fraternal twins. Socioeconomic characteristics are averaged over those years an investor is in our data set. ${ }^{6}$ While identical and fraternal twins are relatively similar with respect to socioeconomic characteristics, we observe substantial cross-sectional variation. We find that the average (median) investor holds about 4 (2)

\footnotetext{
${ }^{5}$ Sales transaction data are not available for 2001 and 2002, and we do not have the exact dates of any of the sales transactions in our data set.

${ }^{6}$ The educational variables are based on the maximum, not an average.
} 
equity securities with a combined value of about $\$ 20,000(\$ 4,000)$ in the portfolio. ${ }^{7}$ About $80 \%$ hold at least one equity mutual fund, and about $40 \%$ hold at least one stock. Finally, we have verified that the socioeconomic characteristics of the twins in our sample are similar to non-twins of the same age and gender who participate in the equity market (not tabulated).

\section{Measures of Investment Behaviors}

In this subsection, we define our measures of investment behaviors. Appendix Table A1 reports detailed definitions and Table 3 reports summary statistics for direct stock holdings as well as all equity investments consisting of direct stock as well as mutual fund holdings.

For direct stock holdings, we measure Diversification as the number of distinct stocks held in an individual's portfolio at the end of a given year. For holdings of stocks and mutual funds, we follow Calvet et al. (2009) and define Diversification as the proportion of equity investments invested in mutual funds as opposed to individual stocks. To reduce measurement error, we calculate the equally weighted average Diversification across all years the individual is in the data set. Summary statistics in Table 3 show that the average investor with direct holdings of stocks holds about three stocks, while across all investors about $70 \%$ of their equity portfolio is invested in mutual funds.

We measure Home Bias by the average proportion invested in Swedish securities. Table 3 shows that for individual stocks the average home bias is $94 \%$, but drops to about $50 \%$ once we include mutual fund investments.

We measure Turnover, i.e., an individual's propensity to trade and turnover the portfolio, following Barber and Odean (2000, 2001). Specifically, for direct stock holdings, we divide, for each individual investor and year, the sales volume (in Swedish krona) during the year by the value of directly held stocks at the beginning of the year. Since we do not have sales prices for mutual funds, we also construct a turnover measure using the number of sales transactions during the year divided by the number of equity securities in the investor's portfolio at the beginning of the year. For each

\footnotetext{
${ }^{7}$ We use the average end-of-year exchange rate 1999-2007 of 8.0179 Swedish krona per U.S. dollar to convert summary statistics. When we estimate models in Section V, all values are in Swedish krona, i.e., not converted to dollars. In terms of size, the portfolios in our data set are comparable to those in other data sets of a broad set of individual investors. For example, in Grinblatt and Keloharju (2009) the average (median) investor holds about 2 (1) equity securities with a combined value of about EUR 24,600 (EUR 1,600) in the portfolio.
} 
measure, we compute the average turnover using all years with available data.

Table 3 reports that for the average investor in our data who holds individual stocks, annual (sales) turnover is about 20\%, a magnitude similar to that reported by Agnew, Balduzzi, and Sundén (2003) for a large set of retirement savings accounts in the U.S., and Grinblatt and Keloharju (2009) for a large sample of individual investors in Finland. Even though many investors in our data trade relatively little, substantial variation exists, as indicated by the cross-sectional standard deviation of about $33 \%$. Some of the investors in our data set therefore likely trade too much, as in, e.g., Odean (1999). That is, they trade more than what is needed to rebalance their portfolios or to satisfy liquidity needs. To control for cross-sectional variation in such reasons to trade, we follow Grinblatt and Keloharju (2009) and control for socioeconomic characteristics that may correlate with rebalancing needs and liquidity demands. The remaining variation may then be considered variation in "excessive" trading.

We measure the Disposition Effect in the spirit of Odean (1998) and Dhar and Zhu (2006). Specifically, at the end of each year during which we observe a sales transaction, we classify securities in an investor's portfolio as winners or losers based on the security's price relative to the approximate price at which the investor acquired the security. ${ }^{8}$ Using data across all years with sales transactions, we calculate for each investor the the proportion of gains realized to the total number of realized and unrealized gains (PGR) as well as the proportion of losses realized to total losses (PLR). The larger the difference between PGR and PLR, the more reluctant a given investor is to realize losses.

Table 3 reveals that we are able to calculate the Disposition Effect only for a subset of investors. The reduction in sample size is due to missing information on purchase prices for securities that are present in an investor's portfolio before 1999, the first year of our sample period, as well as infrequent trading by some investors. The average investor exhibits a disposition effect of about $4 \%$ with respect to direct equity holdings and of about $2 \%$ when including mutual funds. Most importantly, given that the PGR - PLR difference is bounded by -1 and +1 , the standard deviation of about $40 \%$ shows that there is significant variation across individuals with respect to the reluctance to realize losses.

\footnotetext{
${ }^{8}$ Since we do not observe the exact price at which an investors acquires a given security, we use the end-of-year price (averaged between the year before an acquisition and the year of the acquisition) as the reference price.
} 
We measure Performance Chasing by an individual's propensity to purchase securities that have performed well in the recent past. More specifically, each year we sort stocks and equity mutual funds separately into return deciles using the returns during the year. For each investor and year with net increases in holdings of stocks or mutual funds, we calculate the fraction of purchased securities with returns in the top two deciles. The higher that fraction, the more the individual chases performance by overweighting securities with higher recent performance. Performance Chasing is the average fraction over all years with net acquisitions of equity securities. Table 3 shows, on average, about $10-15 \%$ of the securities acquired have shown relatively strong recent performance. Since not all investors make net acquisitions during our sample period, Performance Chasing is only available for a subset of investors

We measure an individual's Skewness Preference as in Kumar (2009). For each investor and year we calculate the proportion of the portfolio that is invested in "lottery" securities, i.e., securities with a below median price as well as above median idiosyncratic volatility and above median skewness. Skewness Preference is the fraction of lottery securities averaged over all years with portfolio data. Table 3 shows that, on average, about $3-4 \%$ of an investor's portfolio is held in lottery securities.

To reduce the dimensionality of some of our analysis, we also construct an index that summarizes the above investment behaviors for each investor with holdings of individual stocks. Specifically, for each of the investment behaviors, we assign a value of zero (no bias), one, or two (most biased), depending on the observed level. For example, for the Disposition Effect, we assign two to investors with a disposition effect over $40 \%$ (one standard deviation above zero), one to investors with a strictly positive disposition effect, and zero otherwise. Appendix Table A1 provides a detailed description of the construction of the Investment Bias Index. If for a given investor, a behavior is missing, we use the median behavior to assign the bias index component (zero, one, or two). An individual's Investment Bias Index is the sum across all the investment behaviors and takes on values between zero and twelve. 


\section{Empirical Methodology}

To decompose the cross-sectional variation in investment behaviors into genetic and environmental components, we model each measure of an investment bias $y_{i j}$ for twin $j$ ( 1 or 2 ) of pair $i$ as a function of observable socioeconomic characteristics $\mathbf{X}_{i j}$ as well as three unobserved effects. We assume that $y_{i j}$ is a function of an additive genetic effect, $a_{i j}$, an effect of the environment common to both twins (e.g., parenting), $c_{i}$, and an individual-specific effect, $e_{i j}$, also capturing idiosyncratic measurement error:

$$
y_{i j}=f\left(\mathbf{X}_{i j}, a_{i j}, c_{i}, e_{i j}\right)
$$

We assume initially that $a_{i j}, c_{i}$, and $e_{i j}$ are uncorrelated with one another and across twin pairs and normally distributed with zero means and variances $\sigma_{a}^{2}, \sigma_{c}^{2}$, and $\sigma_{e}^{2}$, respectively, so that the total residual variance $\sigma^{2}$ is the sum of the three variance components. We later model gene-environment interactions by allowing $a_{i j}, c_{i}$, and $e_{i j}$ to vary with specific, observable experiences or circumstances.

Identifying variation due to $a_{i j}, c_{i}$, and $e_{i j}$ separately is possible due to constraints on the covariances. These constraints are motivated by the genetic similarity of twins as well as assumptions of their upbringing and other aspects of their common environment. Consider two twin pairs $i=1,2$ with twins $j=1,2$ in each pair, where the first is a pair of identical twins and the second is a pair of fraternal twins. The genetic effects are: $a=\left(a_{11}, a_{12}, a_{21}, a_{22}\right)^{\prime}$. Analogously, the common and individual-specific environmental effects are: $c=\left(c_{11}, c_{12}, c_{21}, c_{22}\right)^{\prime}$ and $e=\left(e_{11}, e_{12}, e_{21}, e_{22}\right)^{\prime}$. Identical and fraternal twin pairs differ in their genetic similarity. Identical twins are genetically identical, and the correlation between $a_{11}$ and $a_{12}$ is set to one. Fraternal twins share on average only $50 \%$ of their genes, such that the correlation between $a_{21}$ and $a_{22}$ is 0.5 . For both identical and fraternal twin pairs, an equal effect of the common environment is assumed. As a result, we use the following covariance matrices:

$$
\operatorname{Cov}(a)=\sigma_{a}^{2}\left[\begin{array}{cccc}
1 & 1 & 0 & 0 \\
1 & 1 & 0 & 0 \\
0 & 0 & 1 & 0.5 \\
0 & 0 & 0.5 & 1
\end{array}\right], \operatorname{Cov}(c)=\sigma_{c}^{2}\left[\begin{array}{cccc}
1 & 1 & 0 & 0 \\
1 & 1 & 0 & 0 \\
0 & 0 & 1 & 1 \\
0 & 0 & 1 & 1
\end{array}\right], \operatorname{Cov}(e)=\sigma_{e}^{2}\left[\begin{array}{cccc}
1 & 0 & 0 & 0 \\
0 & 1 & 0 & 0 \\
0 & 0 & 1 & 0 \\
0 & 0 & 0 & 1
\end{array}\right] .
$$


For the measures of investment biases in this study, we assume that $f$ is a linear function:

$$
y_{i j}=\beta_{0}+\beta \mathbf{X}_{i j}+a_{i j}+c_{i}+e_{i j}
$$

where $\beta_{0}$ is an intercept term and $\beta$ measures the effects of the observable socioeconomic characteristics $\left(\mathbf{X}_{i j}\right)$, e.g., age, education, income and wealth. We use maximum likelihood to estimate the model using Mplus (Muthén and Muthén, 2010). Reported standard errors are bootstrapped with 1,000 repetitions.

Finally, we calculate the variance components $A, C$, and $E$. $A$ is the proportion of the total residual variance in an investment bias that is due to an additive genetic factor:

$$
A=\frac{\sigma_{a}^{2}}{\sigma_{a}^{2}+\sigma_{c}^{2}+\sigma_{e}^{2}}
$$

The proportions attributable to the common environment $(C)$ and individual-specific environmental effects $(E)$ are computed analogously.

\section{Results}

In this section, we report our main results with respect to the question to which extent investment biases investors exhibit in real-world financial decisions reflect underlying innate predispositions. For comparison with a large number of papers that have studied investment biases, we focus on measures constructed for individual stocks, but also provide results when including mutual funds.

We first compare correlations between genetically identically investors with correlations between related, but genetically non-identical investors. Such a comparison provides intuitive evidence on the importance of latent genetic factors. We then provide formal estimation results from decomposing investment biases into genetic and environmental variation. Finally, we perform a large number of robustness checks. 


\section{A Evidence from Correlations}

For each investment behavior introduced previously, Figure 1 reports correlations between identical twins as well as same and opposite-sex fraternal twins. We draw several conclusions from the evidence. First, for each measure, we find that the correlation is significantly greater between identical relative to fraternal twins. This difference indicates that to some extent investors display more or less of a given investment bias due to their genetic make-up. On average, the correlation between identical twins is about twice the correlation between fraternal twins. Second, the correlations for same-sex fraternal twins is generally larger than those for opposite-sex twins. This result suggests that gender affects investment behaviors. In our formal model of the origins of investment biases, we will therefore control for gender. In addition, we will provide a robustness check that excludes opposite-sex twins. Finally, we note that the correlation for identical twins is between 25 and $50 \%$, significantly different from one, suggesting that individual-specific experiences and events are also important for the understanding of why investors exhibit investment biases.

\section{B Empirical Decomposition of Investment Biases}

We use the model in equation (2) to empirically decompose the variation in investment behaviors across individuals into genetic and environmental components. In Panel A of Table 4, we report results from a model that only controls for gender and age which explain very little of the variation in investment behaviors. Thus, most of the variation remains unexplained. This unexplained variation is decomposed into genetic and environmental components. For each component, we report its relative contribution to the unexplained variation of each investment behavior. $A$ denotes genetic variation, while $C$ and $E$ denote common and individual-specific environmental variation.

The evidence suggests that variation across individual investors with respect to all six investment biases examined reflects to a significant extent genetic differences between investors. Genetic factors seem to be particularly influential in determining Diversification and Home Bias, where they account for around $45 \%$ of the (unexplained) variation. For the remaining behaviors, genetic variation still accounts for between a quarter and a third of the variation. That is, individuals are to a significant extent born with predispositions that later in life and under the conditions typically experienced 
by an investor in our data set manifest themselves in the investment biases we examine in this paper. The findings also suggest that at least $55 \%$ of the variation in investment behaviors is due to environmental factors, represented by the $C$ and $E$ components. Almost all of the environmental variation reflects individual-specific experiences, circumstances, events, and possibly measurement error. ${ }^{9}$ The $C$ component is insignificant suggesting that upbringing or other aspects of the common environment do not affect investment biases. That is, the notion that children learn investment biases from their parents is inconsistent with the data. ${ }^{10}$

Wealthier, more educated, and generally more sophisticated investors often make better financial decisions and exhibit fewer investment biases (e.g., Agnew (2006), Dhar and Zhu (2006), Kumar (2009), Calvet et al. (2009)). It is possible that certain frictions, such as transaction costs, are less binding for these investors or that these investors have access to better financial advice. At the same time, they likely have superior cognitive abilities which have also been shown to lower investment biases (Grinblatt et al. (2011, 2012)). Importantly, some of the variation in these characteristics, i.e. wealth, education, and, in particular, IQ is due to genetic differences across investors (see, e.g., Bouchard and McGue (1981), Davies et al. (2011), Behrman and Taubman (1989), and Cronqvist and Siegel (2011)). To rule out that our findings with respect to the genetic origins of behavioral biases reflect genetic variation in these characteristics, we repeat the analysis controlling for several of these socioeconomic characteristics. In particular, in addition to age and gender, we control for education, marital status, wealth, and income. ${ }^{11}$ We do not have data on cognitive abilities, but several of the included characteristics, in particular education and wealth, have been shown to be correlated with measures of IQ. The results in Panel B of Table 4 confirm that in particular education and wealth are often associated with lower investment biases. At the same time, the additional controls explain only little of the variation in investment biases, in five out of six cases less than 5\%. Decomposing the remaining unexplained variation yields therefore very similar results

\footnotetext{
${ }^{9}$ Since our data set comes from the Swedish Tax Agency, which in turn obtains the data directly from financial institutions, reporting errors should be relatively rare. To reduce measurement error, we use whenever possible time-series averages (over up to eight years) of annually measured investment behaviors.

${ }^{10}$ The evidence of an insignificant $C$ component is consistent with evidence from behavioral genetics research (e.g., Bouchard et al. (1990)) and recent research on risk preferences (e.g., Barnea, Cronqvist, and Siegel (2010) and Cesarini et al. (2010)).

${ }^{11}$ For the Disposition Effect, we also include Turnover and the Number of Holdings as control (see Dhar and Zhu (2006)).
} 
as in Panel A: Genetic differences remain an important source of variation for all six investment behaviors (still accounting for 25 to $45 \%$ ), while almost all of the remaining environmental variation is individual-specific.

Our results suggest that future research in genetics as well as in economics and the social sciences in general is needed to understand in detail how investment biases arise and how they can possibly be reduced. While recent studies in molecular genetics, using DNA level data, have confirmed the relative importance of genetic differences first documented using twin studies (Jian et al. (2010) and Davies et al. (2011)), the relative variation that can be explained by linear combinations of specific genes that are associated with the outcome of interest is (still) low, rarely exceeding 10\% (Visscher (2008)). This suggests that the latent genetic component that we document for several investment biases likely consists of many genes and possibly their interactions. Interestingly, our results show that first-order socioeconomic characteristics leave most of the observed variation unexplained. This suggests that the environmental factors and mechanisms representing the substantial $E$ component could be similarly complex, possibly consisting of many particular events and circumstances that influence an individual's investment behavior.

Finally, in Table 5, we repeat our analysis for investment behaviors measured across all equity investments, including mutual funds. While much of the existing literature in finance has focused on individual investors' choices with respect to individual stocks, many investors invest in mutual funds as well. It is possible that genetic predispositions are moderated by delegating mainly the selection of specific assets to an outside fund manager. We re-estimate the models previously estimated for stock investments only and find that the relative importance of genetic factors as captured by the $A$ components is lower than what we found for the case of direct stock holdings, but only slightly so. The $A$ component ranges between 16-38\%, depending on the investment behavior. We conclude that genetic differences affect preference or belief differences with respect to direct as well as indirect or delegated equity investments.

In the remainder of the paper, we again focus on measures constructed for individual stocks. We also continue to include the socioeconomic controls first introduced in Panel B of Table 4. 


\section{Robustness}

We provide several robustness checks regarding sample composition, model misspecification, and model assumptions.

\section{C.1 Opposite-Sex Twins}

We noted in Figure 1 that the correlations for same-sex fraternal twins are generally greater than those for opposite-sex twins. A concern is that including opposite-sex twins in our analysis results in an upward bias of the relative importance of genetic factors, as captured by $A$, as identical twins always have the same sex. As a robustness test, we exclude opposite-sex fraternal twins from our sample and re-estimate the above models. Panel A of Table 6 shows that our results are essentially unaltered compared to the estimates reported in Panel B of Table 4.

\section{C.2 Model Misspecification}

Some of the reported $C$ components in Table 4 are exactly zero, reflecting a corner solution as we constrain all variance components to be non-negative. This raises concerns about model misspecification. As a robustness check, we re-estimate the model in equation (2), without nonnegativity constraints on the individual variance components. Table 6 Panel B shows that the emerging negative $C$ components are very small in magnitude $(-3.9 \%$ to $-9.8 \%)$ and never statistically significant from zero, reducing concerns about misspecification bias.

A related concern is that some of the measures of investment behaviors are censored (e.g., Home Bias is between 0 and 1). We have verified that a Tobit model specification results in unchanged, and sometimes stronger, $A$ components (not tabulated).

\section{C.3 Model Assumptions}

Equal Environments Assumption (EEA). If parents or others in an individual's environment treat identical twins more similarly than parents or others treat fraternal twins (along dimensions that are relevant for the investment behaviors we study), then $A$ may be upward biased. This is a well-recognized problem in twin research, and as a result substantial resources have been (and 
continue to be) devoted to tests of the EEA. ${ }^{12}$ From research on IQ and personality, where the EEA has to date been tested most rigorously, the evidence suggests that any bias from violations of the EEA is not of first order importance (e.g., Bouchard (1998)). Specifically, researchers have studied twins reared apart, i.e., twins separated at birth or early in life, for which there is no common parental environment. Such studies often produce heritability estimates similar to those using twins who were reared together (e.g., Bouchard et al. (1990)). Perhaps even more convincingly, recent progress has enabled researchers to construct DNA-based measures of pairwise genetic relatedness, which were then related to different outcomes, e.g., height and IQ (Jian et al. (2010) and Davies et al. (2011)). Differently from twin studies, these studies use unrelated subjects and show without relying on any assumptions such as the EEA that at least $50 \%$ of the variation in the studied outcomes is due to genetic variation. Finally, specialist twin researchers continue to test the EEA. One concern has been that the matched physical appearance of identical twins result in more similar treatment by those who are a part of these individuals' environments, in the end causing more similar outcomes. Using a clever research design, Segal (2012) studies unrelated look-alike individuals, and finds that their correlations for personality measures are much lower than for identical twins, suggesting that identical twins' similarity mostly reflects similarity in their genes, and not similar treatments by others.

Intra-Twin Pair Communication. If identical twins communicate more with one another than fraternal twins, and if such interaction impacts their investments (e.g., Bikhchandani, Hirshleifer, and Welch (1998) and Hong, Kubik, and Stein (2004)), then A may reflect the direct as well as indirect (via increased communication) effects of genetic similarity. We address this concern using two robustness checks. First, we exclude twin pairs with more than $50 \%$ similarity in their portfolios. ${ }^{13}$ Panel $\mathrm{C}$ of Table 6 reveals evidence of a substantial genetic effect even when excluding twins with similar portfolios. Second, we control directly for intra-twin pair communication. To do so, we sort twin pairs into deciles based on intra-twin pair contact frequency (available for a subset of twins from STR) and randomly exclude twins until we have equally many identical and

\footnotetext{
${ }^{12}$ See, e.g., Goldberger (1979) for a discussion of common concerns related to twin studies.

${ }^{13}$ Specifically, we drop twin pairs for whom the sum of the absolute value of portfolio weight differences is less than one (on a range between zero for identical portfolios and two for non-overlapping portfolios).
} 
fraternal pairs in each decile. We repeat this process 100 times and then perform one estimation for each of the 100 samples. Table 6 Panel D reports that the median $A$ components are still large and statistically significant. Only for the Disposition Effect do we no longer find a significant genetic effect once we control for communication, but the sample size for this specific robustness check is very small contributing to the large confidence interval.

\section{C.4 Relatively Large Portfolios}

Investors with relatively small portfolios may not be incentivized to overcome innate predispositions to certain biases. As a robustness check, we therefore exclude all individuals for whom the equity portfolio does not constitute at least $20 \%$ of their total assets. The results in Table Panel E of Table 6 suggest that genetic factors continue to be important even among investors with substantial equity exposure.

\section{Additional Results}

\section{A Behavioral Consistency: Investment Biases and Behaviors in Other Domains}

We examine whether some of the previously analyzed investment biases are in fact facets of broader

behaviors. Specifically, we identify behaviors in domains other than investments, and then we estimate the genetic correlation between investment biases and those behaviors in other domains. An example is the preference for familiarity. As described in Section II, recent papers study the genetic basis of familiarity (e.g., Chew et al. (2011)). We therefore examine if a preference for the familiar in the investment domain is correlated with a preference for familiarity in some other domains, and most importantly, whether genetic factors influencing the Home Bias also affect familiarity preferences in other domains. We consider two measures of familiarity preferences in domains other than investments: the distance between an individual's home location and her birth place, Distance to Birthplace, and an indicator for whether an individual's spouse is born in the same region as the individual herself, Spouse from Home Region.

In Table 7, we report results from decomposing the covariance of these investment and other 
behaviors into components corresponding to genetic effects and effects of common and individualspecific environments. Specifically, we use a bivariate Cholesky decomposition (see Neale and Maes (2004) for details). This model controls for individual socioeconomic characteristics such as income and wealth that may determine both investment behavior and non-investment choices.

We report several results. First, variation in familiarity in other, non-investment, domains reflects significant genetic differences: $40 \%$ for home location and 15\% for choice of spouse. Second, Home Bias and Distance to Birthplace are significantly negatively correlated, suggesting that those with relatively more local stocks also have a stronger preference for a home location close to their birth place. Finally, and most importantly, the significantly negative genetic correlation between both behaviors suggests that the genetic factors affecting Home Bias also affect Distance to Birthplace. While we do not find an overall correlation between Home Bias and Spouse from Home Region, we find a large, though statistically not significant, positive genetic correlation between both behaviors.

This evidence is important because it suggests that behavioral consistency across several domains might be due to genetic endowments. That is, individuals are born with certain predispositions that affect their behaviors in many domains, including investments. The finding is also consistent with the view that preferences or behavior reflect psychological mechanisms that have been shaped by evolutionary forces whose effects extend to choices, such as financial investment decisions, that did not exist in ancient times.

\section{B Moderators of Genetic Effects of Investment Biases}

Our main results in Table 4 suggest that, depending on the specific investment behavior, genetic variation accounts for 25 to $45 \%$ of the variation across individuals. It is important to note that the relative importance of genetic relative to non-genetic factors can vary across different investors or environments. Cunha and Heckman (2010) go as far as concluding that "the nature versus nurture distinction is obsolete" (p. 3), and they argue that the notion that genes are moderated by environments should receive more attention in economic research. For an extensive review of research on so called "gene-environment interactions", we refer to Rutter (2006). 


\section{B.1 Work Experience in Finance}

Does work experience in a corporate treasury department or in the finance industry reduce the impact of genetic predispositions with respect to investment biases? We use data on an individual's occupation, based on the International Standard Classification of Occupations (ISCO-88) by the International Labour Organization (ILO) and available for a subset of our sample, to identify twins with work experience related to finance. We re-estimate the above models including only twins with relevant finance experience. To increase the sample size we consider direct as well as indirect holdings of equity. We include the same socioeconomic controls as previously.

Table 8 reports the corresponding results. For twins with financial experience, the relative importance of genetic factors is substantially smaller for each of the investment behaviors than in case of the general population (see Table 5). ${ }^{14}$ Only for Skewness Preference does the $A$ component remain marginally significant at 15\%. For Diversification, Home Bias, and Performance Chasing, genetic differences seem to account for almost none of the variation. For Turnover, the $A$ share decreases to $10 \%$ and is no longer statistically significant. At the same time, the similar work environment experienced by this specific subset of twins generates pair-specific commonality in their behavior.

While we cannot rule out that the selection into specific occupations reduces the relevant genetic variation in this particular sub-sample, the evidence in Table 8 is certainly consistent with work experience with finance reducing the impact of genetic predispositions with respect to investment biases.

\section{B.2 General Education}

Education is a potentially important moderator of genetic effects. For example, Johnson et al. (2010) report, in a different context, that education reduces expressions of genetic predispositions to poor health. Individuals may be born with a propensity to poor health, but education enables them to reduce such genetic propensities. In our paper, it is therefore interesting to examine the extent to which education moderates the importance of genetic factors for investment biases.

\footnotetext{
${ }^{14}$ We have too few twin pairs with occupational financial experience to estimate a separate model for Disposition Effect.
} 
In terms of empirical methodology, we rely on the gene-environment interaction model by Purcell (2002). Figure 2 provides a graphical description of the model. In contrast with the model outlined in equation (2), a moderator $(M)$, here education, interacts with the unobservable genetic and environmental factors of the investment behavior $(y)$. The model allows education and the investment behavior to be correlated via exposure of the investment behavior to the unobservable genetic and environmental factors of the moderator. That is, we include all twins with non-missing education data and account for the possibility that educational outcomes and investment behaviors are not independent. Finally, we use regressions to remove the effect of the socioeconomic characteristics used as control variables in Table 4, with the exception of educational characteristics (not tabulated).

We measure educational outcome with Years of Education which is based on the highest completed degree. ${ }^{15}$ To reduce the dimensionality of the analysis, we employ the previously introduced Investment Bias Index that summarizes the six investment behaviors for each individual.

Figure 3 reports a graphical summary of the results, displaying the absolute size of the genetic and environmental variances (vertical axis) as a function of Years of Education (horizontal axis). We find that education does not reduce the effect of genetic predisposition to investment biases. In particular, the detailed results of the model estimation in Appendix Table A2 suggest a small increase in genetic variance due to education. ${ }^{16}$ Further, Figure 3 shows that the variance of common environmental effects also increases slightly, but in a statistically insignificant way, as individuals obtain more education, while the individual-specific environmental variation remains unchanged.

These results suggest that differences in genetic propensity to certain investment biases do not decrease with an increase in general educational achievement. Importantly, while professional finance experience seems to reduce genetic propensities to investment biases, general education does not seem to have a similar effect.

\footnotetext{
${ }^{15}$ For some individuals, we have information on their highest degree, but not on Years of Education. We use a linear regression model to estimate Years of Education for those individuals. See Appendix Table A1 for details.

${ }^{16}$ This conclusion is based on a significantly positive estimate of alpha_ $u$ which has the same sign as the estimate of $a_{-} u$. For estimation purposes, Years of Education is expressed in units of 10 years.
} 


\section{Evidence from Discordant Twin Pair Research Design}

While our results demonstrate the important role genetic factors play in determining investment behaviors, they also show that substantial variation observed among the individuals in our sample is due to individual-specific environmental effects, captured by the $E$ component in our variance decomposition results. Identifying the specific circumstances, experiences, or events as well as the mechanisms through which they impact investment choices is important for better models of investor behavior as well as public policy. Given that differences in education, net-worth, and income explain typically less than $10 \%$ of the total variation, substantial work seems to be left for social scientists. One particular challenge researchers face when trying to identify causal effects of specific environmental conditions is that individuals have been shown to self-select into experiences and even life events partly as a function of their genetic predispositions. Consequently, controlling for genetic factors is important in the search of environmental factors that matter for investment behaviors. Using the socioeconomic variables included in our model, we show how genetically informed data, such as twin data, can be used to address such confounding effects.

Using data on identical twins allows us to apply a "discordant twin-pair research design" that approximates a natural experiment. The approach allows to compare the investment behaviors of twin pairs who are discordant on, e.g., education, but match on genes and shared environment. The design provides a useful analogue to a counterfactual design, and the absence of an association within discordant twin pairs means that a previously observed association between an individual characteristic and investment behavior is attributable to common genetic or shared environmental factors.

We select all identical twins from our sample of twins with direct stock holdings. We observe that about $20 \%$ of them are discordant with respect to their education. We use a standard linear regression model to regress Investment Bias Index on a set of socioeconomic characteristics, including education. The first column in Table 9 reports results. One of the important results is that college degree is significantly inversely related to investment biases.

In the second column, we report evidence from a discordant twin pair research design for a pair 
$i$ of identical twins $(j=1,2)$ that were reared together. ${ }^{17}$ If an investment bias $y_{i j}$ is linear in observable socioeconomic characteristics and unobservable genetic and environmental effects, $a_{i}, c_{i}$, and $e_{i j}$, we can eliminate the genetic and shared environmental effects, $a_{i}$ and $c_{i}$, by considering the difference between the twins in a pair:

$$
\begin{gathered}
y_{i j}=\beta_{0}+\beta \mathbf{X}_{i j}+a_{i}+c_{i}+e_{i j} \\
y_{i 1}-y_{i 2}=\beta\left(\mathbf{X}_{i 1}-\mathbf{X}_{i 2}\right)+e_{i 1}-e_{i 2} .
\end{gathered}
$$

Comparing the estimates in the first and second columns, we conclude that the effects of a college degree is reduced once we eliminate genetic and shared environmental effects. That is, the effects of college degree on investment biases reported in the first column are confounded, and attributable to unobservable genetic or shared environmental factors.

The specific result with respect to education suggests that general education, as measured by a college degree, does not cause a reduction in investment biases. This result does not suggest that more targeted financial literacy initiatives cannot affect individuals' investment choices. More generally, though, the evidence presented here suggests that genetically informed data can play an important role when evaluating the causal effect of circumstances, experiences, or events with respect to investment behavior.

\section{Conclusion}

In this paper, we have examined the following question: Why do individuals exhibit investment biases? Our focus in this paper has been on the relative importance of genetic and environmental factors. For a long list of well-recognized investment biases (e.g., the reluctance to realize losses, performance chasing, and the home bias), we find that genetic factors explain up to $45 \%$ of the variation across individual investors. But the relative importance of genetic relative to environmental factors is found to vary substantially across different investors. For example, among investors with work experience in finance, we find a significant reduction of the relative amount of genetic variation,

\footnotetext{
${ }^{17}$ See Taubman (1976) for an early application of this empirical methodology.
} 
which is consistent with practical experience in finance moderating genetic predispositions to investment biases. Interestingly, we do not find that general education has a similar moderating effect.

These results have implications for the design of public policy in the domain of financial literacy (e.g., Lusardi and Mitchell (2007) and Van Rooij, Lusardi, and Alessie (2011)). Specifically, the findings suggest that policy should be designed considering the existence of genetic predispositions as well as the potential difficulties in reducing those predispositions through general education. Recent research has reached similar conclusions. For example, Bhattacharya et al. (2012) show in a large field study that investors who are offered unbiased investment advice often are not interested in the advice and even those that are interested rarely follow the advice.

Our evidence is consistent with evolutionary arguments of behavior as in Rayo and Becker (2007) and Brennan and Lo (2011). Nature selects fitness maximizing behaviors, i.e., behaviors associated with a reproductive advantage relative to alternative behaviors. What in finance research is referred to as "biases" may indeed be manifestations of fitness maximizing psychological mechanisms. Consistent with this view of investment biases as partly innate features of human behavior, we find that the genetic factors that influence investment biases also affect behaviors in other, non-investment, domains.

So what explains the genetic effects we find? As argued in Table 1 of our paper, recent research in behavioral genetics has linked specific genes to several of the psychological mechanisms that may manifest themselves as investment biases. That is, some individuals are endowed with genes linked to overconfidence, sensation seeking, or loss aversion, and these genes may manifest themselves in the individual's investment behavior, as well as in the individual's behavior in non-investment domains. An additional explanation, which is consistent with recent work in finance (e.g., Grinblatt, Keloharju, and Linnainmaa $(2011,2012))$, is that IQ is genetic, which results in genetic variation in investment biases.

While a significant portion of our paper emphasizes genetic predispositions to investment biases, it is important to also recognize that the environment an investor experiences also affects investment biases, either as a moderator of genetic predispositions or directly. Indeed, more than $50 \%$ of the 
variation in investment biases across investors is attributable to individual-specific experiences and events. We encourage future research in this field to dig deeper into which specific individual experiences (e.g., early in an individual's life or career) are most important when it comes to shaping investment behavior. 


\section{References}

Agnew, J., Balduzzi, P., Sundén, A., 2003. Portfolio choice and trading in a large 401(k) plan. American Economic Review 93 (1), 193-215.

Agnew, J. R., 2006. Do behavioral biases vary across individuals? Evidence from individual level 401(k) data. Journal of Financial and Quantitative Analysis 41 (4), 939.

Barber, B., Lee, Y., Liu, Y., Odean, T., 2009. Just how much do individual investors lose by trading? Review of Financial Studies 22 (2), 609.

Barber, B. M., Odean, T., 2000. Trading is hazardous to your wealth: The common stock investment performance of individual investors. Journal of Finance 55 (2), 773-806.

Barber, B. M., Odean, T., 2001. Boys will be boys: Gender, overconfidence, and common stock investment. Quarterly Journal of Economics 116 (1), 261-292.

Barberis, N., Huang, M., 2008. Stocks as lotteries: The implications of probability weighting for security prices. American Economic Review 98 (5), 2066-2100.

Barnea, A., Cronqvist, H., Siegel, S., 2010. Nature or nurture: What determines investor behavior? Journal of Financial Economics 98, 583-604.

Behrman, J., Taubman, P., 1989. Is schooling "mostly in the genes"? Nature-nurture decomposition using data on relatives. Journal of Political Economy 97, 1425-1446.

Benartzi, S., 2001. Excessive extrapolation and the allocation of 401(k) accounts to company stock. Journal of Finance 56 (5), 1747-1764.

Bhattacharya, U., Hackethal, A., Kaesler, S., Loos, B., Meyer, S., 2012. Is unbiased financial advice to retail investors sufficient? Answers from a large field study. Review of Financial Studies 25, 975-1032.

Bikhchandani, S., Hirshleifer, D., Welch, I., 1998. Learning from the behavior of others: Conformity, fads, and informational cascades. Journal of Economic Perspective 12 (3), 151-170.

Bisin, A., Verdier, T., 2000. Beyond the melting pot: Cultural transmission, marriage, and the evolution of ethnic and religious traits. Quarterly Journal of Economics 115 (3), 955-988.

Bortolus, R., Parazzini, F., Chatenoud, L., Benzi, G., Bianchi, M., Marini, A., 1999. The epidemiology of multiple births. Human Reproduction Update 5 (2), 179.

Bouchard, T. J., 1998. Genetic and environmental influences on adult intelligence and special mental abilities. Human Biology 70, 257-279.

Bouchard, T. J., Lykken, D. T., McGue, M., Segal, N. L., Tellegen, A., 1990. Sources of human psychological differences: The Minnesota study of twins reared apart. Science 250, 223-228.

Bouchard, T. J., McGue, M., 1981. Familial studies of intelligence: A review. Science 212, 10551059.

Brennan, T. J., Lo, A. W., 2011. The origin of behavior. Quarterly Journal of Finance 1, 55-108. 
Calvet, L. E., Campbell, J. Y., Sodini, P., 2009. Measuring the financial sophistication of households. American Economic Review 99, 393-398.

Cesarini, D., Johannesson, M., Lichtenstein, P., Sandewall, O., Wallace, B., 2010. Genetic variation in financial decision making. Journal of Finance 65, 1725-1754.

Cesarini, D., Johannesson, M., Lichtenstein, P., Wallace, B., 2009. Heritability of overconfidence. Journal of the European Economic Association 7 (2-3), 617-627.

Cesarini, D., Johannesson, M., Magnusson, P. K. E., Wallace, B., 2012. The behavioral genetics of behavioral anomalies. Management Science 58, 21-34.

Chen, M. K., Lakshminarayanan, V., Santos, L. R., 2006. How basic are behavioral biases? Evidence from Capuchin monkey trading behavior. Journal of Political Economy 114 (3), 517-537.

Chew, S. H., Ebstein, R. P., Zhong, S., 2011. Ambiguity aversion and familiarity bias: Evidence from behavioral and gene association studies. Journal of Risk and Uncertainty 44, 1-18.

Cronqvist, H., Siegel, S., 2011. The origins of savings behavior. Working paper, University of Washington, Michael G. Foster School of Business.

Cunha, F., Heckman, J., 2010. Investing in our young people. In: Reynolds, A. (Ed.), Cost Effective Early Childhood Programs in the First Decade: A Human Capital Integration. Cambridge University Press.

Davies, G., Tenesa, A., Payton, A., Yang, J., Harris, S. E., Liewald, D., Ke, X., Le Hellard, S., Christoforou, A., Luciano, M., McGhee, K., Lopez, L., Gow, A. J., Corley, J., Redmond, P., Fox, H. C., Haggarty, P., Whalley, L. J., McNeill, G., Goddard, M. E., 2011. Genome-wide association studies establish that human intelligence is highly heritable and polygenic. Molecular Psychiatry 16 (10), $996-1005$.

Derringer, J., Krueger, R., Dick, D., Saccone, S., Grucza, R. A., Agrawal, A., Lin, P., Almasy, L., Edenberg, H., Foroud, T., Nurnberger, J. I., Hesselbrock, V., Kramer, J., Kuperman, S., Porjesz, B., Schuckit, M., Bierut, L., 2010. Predicting sensation seeking from dopamine genes: A candidate-system approach. Psychological Science 21.

Dhar, R., Zhu, N., 2006. Up close and personal: Investor sophistication and the disposition effect. Management Science 52 (5), 726-740.

Ellsberg, D., 1961. Risk, ambiguity, and the Savage axioms. Quarterly Journal of Economics, 643-669.

Fox, C. R., Tversky, A., 1995. Ambiguity aversion and comparative ignorance. Quarterly Journal of Economics 110 (3), 585-603.

French, K. R., Poterba, J. M., 1991. Investor diversification and international equity markets. American Economic Review 81 (2), 222-226.

Fulker, D. W., Eysenck, S. B. G., Zuckerman, M., 1980. A genetic and environmental analysis of sensation seeking. Journal of Research in Personality 14, 261-281. 
Gervais, S., Odean, T., 2001. Learning to be overconfident. Review of Financial Studies 14 (1), 1-27.

Goldberger, A., 1979. Heritability. Economica 46 (184), 327-347.

Griffin, D., Tversky, A., 1992. The weighting of evidence and the determinants of confidence. Cognitive Psychology 24, 411-435.

Grinblatt, M., Keloharju, M., 2009. Sensation seeking, overconfidence, and trading activity. Journal of Finance 64, 549-578.

Grinblatt, M., Keloharju, M., Linnainmaa, J., 2011. IQ and stock market participation. Journal of Finance 66 (6), 2121-2164.

Grinblatt, M., Keloharju, M., Linnainmaa, J. T., 2012. IQ, trading behavior, and performance. Journal of Financial Economics 104 (2), 339-362.

Harbaugh, W., Krause, K., Vesterlund, L., 2001. Are adults better behaved than children? Age, experience, and the endowment effect. Economics Letters 70 (2), 175-181.

Heath, C., Tversky, A., 1991. Preferences and beliefs: Ambiguity and competence in choice under uncertainty. Journal of Risk and Uncertainty 4 (1), 5-28.

Hirshleifer, D., Luo, G., 2001. On the survival of overconfident traders in a competitive securities market. Journal of Financial Markets 4 (1), 73-84.

Hong, H., Kubik, J. D., Stein, J. C., 2004. Social interaction and stock-market participation. Journal of Finance 59 (1), 137-163.

Huberman, G., 2001. Familiarity breeds investment. Review of Financial Studies 14 (3), 659-680.

Jian, Y., Benyamin, B., McEvoy, B. P., Gordon, S., Henders, A. K., Nyholt, D. R., Madden, P. A., Heath, A. C., Martin, N. G., Montgomery, G. W., Goddard, M. E., Visscher, P. M., 2010. Common snps explain a large proportion of the heritability for human height. Nature Genetics $42(7), 565-569$.

Johnson, D. D. P., Fowler, J. H., 2011. The evolution of overconfidence. Nature, 317320.

Johnson, W., Kyvik, K. O., Mortensen, E. L., Skytthe, A., Batty, G. D., Deary, I. J., 2010. Education reduces the effects of genetic susceptibilities to poor physical health. International Journal of Epidemiology 39 (2), 406-414.

Kahneman, D., Tversky, A., 1979. Prospect theory: An analysis of decision under risk. Econometrica 47 (2), 263-292.

Kumar, A., 2009. Who gambles in the stock market? Journal of Finance 64 (4), 1889-1933.

Lewis, K., 1999. Trying to explain home bias in equities and consumption. Journal of Economic Literature 37 (2), 571-608.

Lichtenstein, P., Sullivan, P. F., Cnattingius, S., Gatz, M., Johansson, S., Carlström, E., Björk, C., Svartengren, M., Wolk, A., Klareskog, L., de Faire, U., Schalling, M., Palmgren, J., Pedersen, N. L., 2006. The Swedish twin registry in the third millennium: An update. Twin Research and Human Genetics 9, 875-882. 
Lusardi, A., Mitchell, O. S., 2007. Financial literacy and retirement preparedness: Evidence and implications for financial education. Business Economics 42, 35-44.

McDermott, R., Fowler, J., Smirnov, O., 2008. On the evolutionary origin of prospect theory preferences. Journal of Politics 70 (2), 335-50.

Muthén, L., Muthén, B., 2010. Mplus user's guide (6th ed.).

Neale, M. C., Maes, H. H. M., 2004. Methodology for Genetic Studies of Twins and Families. Kluwer Academic Publishers B.V., Dordrecht, The Netherlands.

Odean, T., 1998. Are investors reluctant to realize their losses? Journal of Finance 53 (5), 1775-1798.

Odean, T., 1999. Do investors trade too much? American Economic Review 89, 1279-1298.

Patel, J., Zeckhauser, R. J., Hendricks, D., 1991. The rationality struggle: Illustrations from financial markets. American Economic Review 81 (2), 232-236.

Purcell, S., 2002. Variance components models for geneenvironment interaction in twin analysis. Twin Research 5, 554-571.

Rayo, L., Becker, G., 2007. Evolutionary efficiency and happiness. Journal of Political Economy $115(2)$.

Robson, A. J., 2001. The biological basis of economic behavior. Journal of Economic Literature 29, $11-33$.

Rutter, M., 2006. Genes and behavior: Nature/nurture interplay explained. Blackwell Publishers, Oxford, UK.

Segal, N. L., 2012. Personality similarity in unrelated look-alike pairs: Addressing a twin study challenge. Forthcoming Personality and Individual Differences.

Shefrin, H., Statman, M., 1985. The disposition to sell winners too early and ride losers too long: Theory and evidence. Journal of Finance, 777-790.

Slutske, W. S., Eisen, S., True, W. R., Lyons, M. J., Goldberg, J., Tsuang, M., 2000. Common genetic vulnerability for pathological gambling and alcohol dependence in men. Archives of General Psychiatry 7, 666-673.

Taubman, P., 1976. The determinants of earnings: Genetics, family, and other environments: A study of white male twins. American Economic Review 66 (5), 858-870.

Thaler, R. H., 1985. Mental accounting and consumer choice. Marketing Science 4 (3), 199-214.

Tversky, A., Kahneman, D., 1974. Judgment under uncertainty: Heuristics and biases. Science 211, $453-458$.

Tversky, A., Kahneman, D., 1992. Advances in prospect theory: Cumulative representation of uncertainty. Journal of Risk and Uncertainty 5 (4), 297-323. 
Van Rooij, M., Lusardi, A., Alessie, R., 2011. Financial literacy and stock market participation. Journal of Financial Economics 101, 449-472.

Visscher, P. M., 2008. Sizing up human height variation. Nature Genetics 40 (5), 489-490.

Waldman, M., 1994. Systematic errors and the theory of natural selection. American Economic Review, 482-497.

Zhong, S., Israel, S., Xue, H., Sham, P., Ebstein, R., Chew, S., 2009. A neurochemical approach to valuation sensitivity over gains and losses. Proceedings of the Royal Society B: Biological Sciences 276 (1676), 4181. 
Table 1

The Genetic Basis of Investment Biases

\begin{tabular}{|c|c|c|c|}
\hline Investment behavior & Psychological mechanism(s) & Gene(s) & Empirical evidence \\
\hline \multirow[t]{2}{*}{ Insufficient diversification } & Ambiguity aversion & DRD5 (microsatellite marker); ESR2 (CA repeat) & Chew et al. (2011) \\
\hline & Familiarity & SLC6A4 (5-HTTLPR indel) & Chew et al. (2011) \\
\hline \multirow[t]{3}{*}{ Excessive trading } & Overconfidence & & Twin study design: Cesarini et al. (2009) \\
\hline & Sensation seeking & Multiple SNPs in 4 dopamine genes & Derringer et al. (2010) \\
\hline & & & Twin study design: Fulker et al. (1980) \\
\hline \multirow[t]{5}{*}{ Disposition effect } & Prospect theory & 9-repeat vs. 10-repeat allele of DAT1 & Zhong et al. (2009) \\
\hline & & 10-repeat vs. 12-repeat allele of STin2 & Zhong et al. (2009) \\
\hline & & & Loss aversion in Capuchin monkeys (Chen et al. (2006)) \\
\hline & Mental accounting / Framing & & Narrow framing in Capuchin monkeys (Lakshminarayanan et al. (2011)) \\
\hline & & & Twin study design: Cesarini et al. (2012) \\
\hline \multirow{2}{*}{ Performance chasing } & Excessive extrapolation & & \\
\hline & Hot hands fallacy & & \\
\hline \multirow[t]{2}{*}{ Skewness preference } & Cumulative prospect theory & Monoamine oxidase $A$ (4 repeat) & Zhong et al. (2009) \\
\hline & & & Twin study design: Slutske et al. (2000) \\
\hline
\end{tabular}

Table 1 provides information on existing evidence from behavioral genetics with respect to investment behaviors examined in this paper. 
Table 2

Summary Statistics

Panel A: Number of Twins by Zygosity and Gender

\begin{tabular}{|c|c|c|c|c|c|c|c|c|}
\hline & \multirow[t]{2}{*}{ All Twins } & \multicolumn{3}{|c|}{ Identical Twins } & \multicolumn{4}{|c|}{ Fraternal Twins } \\
\hline & & Male & Female & Total & $\begin{array}{c}\text { Same Sex: } \\
\text { Male }\end{array}$ & $\begin{array}{c}\text { Same Sex: } \\
\text { Female }\end{array}$ & $\begin{array}{l}\text { Opposite } \\
\text { Sex }\end{array}$ & Total \\
\hline Number of twins $(N)$ & 30,416 & 4,066 & 5,206 & 9,272 & 4,522 & 5,326 & 11,296 & 21,144 \\
\hline Fraction (\%) & $100 \%$ & $13 \%$ & $17 \%$ & $30 \%$ & $15 \%$ & $18 \%$ & $37 \%$ & $70 \%$ \\
\hline
\end{tabular}

Panel B: Socioeconomic Characteristics and Equity Portfolio Characteristics

\begin{tabular}{|c|c|c|c|c|c|c|c|}
\hline \multirow[b]{2}{*}{ Variable } & \multirow{2}{*}{$\begin{array}{c}\text { All Twins } \\
N\end{array}$} & \multicolumn{3}{|c|}{ Identical Twins } & \multicolumn{3}{|c|}{ Fraternal Twins } \\
\hline & & Mean & Median & Std. Dev. & Mean & Median & Std. Dev. \\
\hline Age & 30,416 & 47.08 & 48.00 & 17.64 & 53.06 & 55.00 & 15.51 \\
\hline Less than High School & 30,416 & 0.15 & 0.00 & 0.35 & 0.20 & 0.00 & 0.40 \\
\hline High School & 30,416 & 0.22 & 0.00 & 0.41 & 0.26 & 0.00 & 0.44 \\
\hline College or more & 30,416 & 0.58 & 1.00 & 0.49 & 0.47 & 0.00 & 0.50 \\
\hline No Education Data available & 30,416 & 0.06 & 0.00 & 0.23 & 0.06 & 0.00 & 0.24 \\
\hline Married & 30,416 & 0.46 & 0.00 & 0.50 & 0.54 & 1.00 & 0.50 \\
\hline Disposable Income (USD) & 30,416 & 31,379 & 25,476 & 27,592 & 35,203 & 27,678 & 35,449 \\
\hline Financial Assets (USD) & 30,416 & 40,759 & 14,537 & 155,296 & 48,062 & 17,342 & 442,298 \\
\hline Total Assets (USD) & 30,416 & 124,351 & 71,883 & 252,478 & 142,603 & 83,504 & 576,198 \\
\hline Total Debt (USD) & 30,416 & 31,802 & 16,020 & 68,330 & 30,396 & 13,759 & 149,778 \\
\hline Net Worth (USD) & 30,416 & 92,549 & 42,961 & 223,277 & 112,207 & 56,417 & 516,665 \\
\hline Number of Stocks and Equity Mutual Funds & 30,416 & 3.56 & 2.33 & 3.80 & 3.62 & 2.25 & 3.97 \\
\hline Value of Stocks and Equity Mutual Funds (USD) & 30,416 & 16,841 & 3,662 & 109,292 & 24,815 & 4,159 & 663,773 \\
\hline Number of Stocks & 12,378 & 3.32 & 1.89 & 3.91 & 3.42 & 1.89 & 4.15 \\
\hline Value of Stocks (USD) & 12,378 & 22,558 & 2,825 & 163,360 & 29,218 & 2,819 & 543,596 \\
\hline Number of Equity Mutual Funds & 23,870 & 2.41 & 1.89 & 1.84 & 2.34 & 1.80 & 1.86 \\
\hline Value of Equity Mutual Funds (USD) & 23,870 & 7,018 & 2,059 & 20,160 & 7,788 & 2,292 & 17,304 \\
\hline
\end{tabular}

Table 2 Panel A provides information on the number of identical and non-identical twins used in this study. Panel B provides summary statistics for several socioeconomic characteristics and portfolio characteristics, separately for identical and non-identical twins. All variables are defined in detail in Appendix Table A1. 
Table 3

Investment Behaviors

\begin{tabular}{|c|c|c|c|c|c|c|c|}
\hline & $\begin{array}{l}\text { All Twins } \\
N\end{array}$ & \multicolumn{3}{|c|}{ Identical Twins } & \multicolumn{3}{|c|}{ Fraternal Twins } \\
\hline \multicolumn{8}{|l|}{ Stocks } \\
\hline Diversification & 12,378 & 3.32 & 1.89 & 3.91 & 3.42 & 1.89 & 4.15 \\
\hline Home Bias & 12,378 & 0.94 & 1.00 & 0.16 & 0.94 & 1.00 & 0.15 \\
\hline Turnover & 11,508 & 0.20 & 0.03 & 0.35 & 0.17 & 0.02 & 0.33 \\
\hline Disposition Effect & 782 & 0.04 & 0.00 & 0.38 & 0.05 & 0.00 & 0.47 \\
\hline Performance Chasing & 6,672 & 0.15 & 0.00 & 0.22 & 0.14 & 0.00 & 0.22 \\
\hline Skewness Preference & 12,378 & 0.04 & 0.00 & 0.10 & 0.03 & 0.00 & 0.10 \\
\hline Investment Bias Index & 12,378 & 4.67 & 5.00 & 1.49 & 4.58 & 5.00 & 1.43 \\
\hline \multicolumn{8}{|c|}{ Stocks and Equity Mutual Funds } \\
\hline Diversification & 30,416 & 0.70 & 0.93 & 0.38 & 0.67 & 0.89 & 0.39 \\
\hline Home Bias & 30,416 & 0.51 & 0.47 & 0.30 & 0.53 & 0.49 & 0.31 \\
\hline Turnover & 28,108 & 0.27 & 0.17 & 0.38 & 0.25 & 0.14 & 0.37 \\
\hline Disposition Effect & 3,086 & 0.02 & 0.00 & 0.43 & 0.02 & 0.00 & 0.43 \\
\hline Performance Chasing & 25,530 & 0.10 & 0.00 & 0.16 & 0.10 & 0.00 & 0.16 \\
\hline Skewness Preference & 30,416 & 0.05 & 0.00 & 0.10 & 0.06 & 0.00 & 0.10 \\
\hline
\end{tabular}

Table 3 reports summary statistics for the main measures of investment behavior, Diversification, Home Bias, Turnover, Disposition Effect, Performance Chasing, and Skewness Preference as well as the Investment Bias Index. Diversification and Turnover are measured differently for stocks and stocks and equity mutual funds. See Appendix Table A1 for a detailed definition of all variables. 
Table 4

Decomposition of Investment Behaviors

Panel A: Controlling for Gender and Age

\begin{tabular}{|c|c|c|c|c|c|c|}
\hline & $\begin{array}{l}\text { Diver- } \\
\text { sification }\end{array}$ & $\begin{array}{l}\text { Home } \\
\text { Bias }\end{array}$ & Turnover & $\begin{array}{c}\text { Disposition } \\
\text { Effect }\end{array}$ & $\begin{array}{c}\text { Performance } \\
\text { Chasing }\end{array}$ & $\begin{array}{l}\text { Skewness } \\
\text { Preference }\end{array}$ \\
\hline \multirow[t]{2}{*}{ Intercept } & 1.916 & 0.912 & 0.152 & -0.146 & 0.126 & 0.012 \\
\hline & 0.344 & 0.017 & 0.031 & 0.161 & 0.030 & 0.008 \\
\hline \multirow[t]{2}{*}{ Male } & 0.553 & 0.011 & 0.078 & -0.038 & 0.026 & 0.012 \\
\hline & 0.074 & 0.003 & 0.006 & 0.034 & 0.005 & 0.002 \\
\hline \multirow[t]{2}{*}{ Age } & 0.220 & 0.010 & 0.017 & 0.098 & 0.012 & 0.013 \\
\hline & 0.151 & 0.007 & 0.012 & 0.064 & 0.012 & 0.003 \\
\hline \multirow[t]{2}{*}{ Age - squared } & 0.001 & -0.001 & -0.003 & -0.010 & -0.002 & -0.002 \\
\hline & 0.016 & 0.001 & 0.001 & 0.006 & 0.001 & 0.000 \\
\hline Fraction of Unexplained Variance & 0.992 & 0.990 & 0.977 & 1.000 & 0.989 & 1.000 \\
\hline \multirow[t]{2}{*}{ A Share } & 0.437 & 0.456 & 0.254 & 0.294 & 0.303 & 0.279 \\
\hline & 0.099 & 0.053 & 0.027 & 0.135 & 0.091 & 0.051 \\
\hline \multirow[t]{2}{*}{ C Share } & 0.091 & 0.000 & 0.000 & 0.000 & 0.102 & 0.000 \\
\hline & 0.066 & 0.028 & 0.000 & 0.057 & 0.066 & 0.029 \\
\hline \multirow[t]{2}{*}{ E Share } & 0.471 & 0.544 & 0.746 & 0.706 & 0.595 & 0.721 \\
\hline & 0.043 & 0.037 & 0.027 & 0.105 & 0.038 & 0.034 \\
\hline$N$ & 12,378 & 12,378 & 11,508 & 782 & 6,672 & 12,378 \\
\hline
\end{tabular}


Table 4 (continued)

Panel B: Controlling for Socioeconomic Characteristics

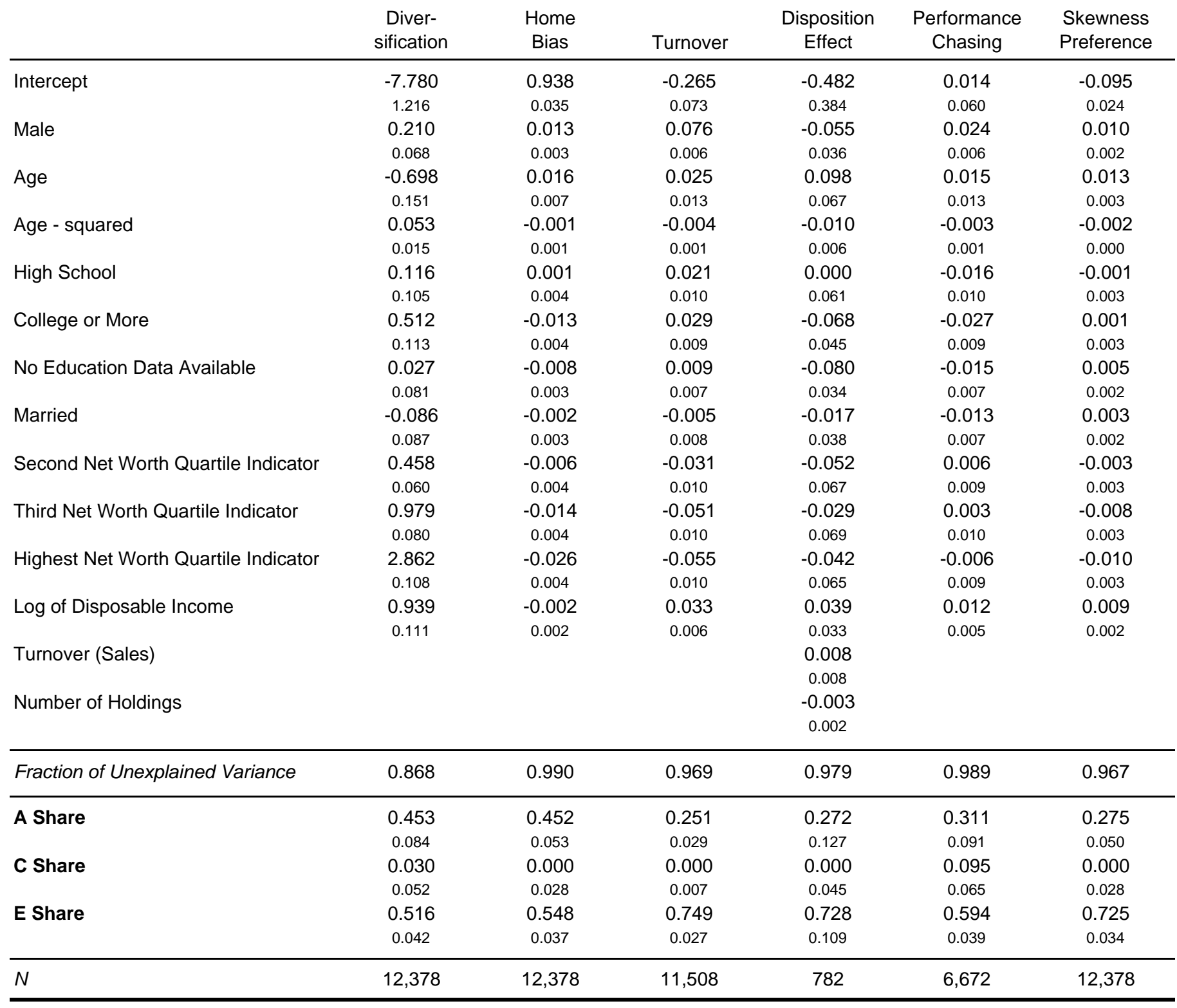

Table 4 reports results from maximum likelihood estimation. The different investment behaviors are modeled as linear functions of observable socioeconomic variables and random effects representing additive genetic effects (A), shared environmental effects (C), as well as an individual-specific error (E). For each estimated model, we report the coefficient estimates for the socioeconomic variables, the Fraction of Variance Unexplained, i. e. the amount of total variation that cannot be explained by the observable independent variables, and the fraction of this unexplained variance that is due to unobserved genetic and environmental effects $(A$ Share - for the additive genetic effect, $C$ Share - for common environmental effect, $E$ Share - for the individual-specific environmental effect) as well as the corresponding bootstrapped standard errors (1,000 resamples). Only direct stock holdings are considered in the measurement of the different investment behaviors. Panel A and B differ only with respect to the included control variables. All variables are defined in Appendix Table A1. $N$ provides the number of observations used in each estimation. 
Table 5

Stocks and Mutual Funds

Variance Components

\begin{tabular}{lcccc}
\multicolumn{1}{c}{ Model } & $N$ & $A$ - Share & $C$ - Share & $E$ - Share \\
\hline Diversification & 30,416 & 0.379 & 0.020 & 0.601 \\
& & 0.032 & 0.021 & 0.015 \\
Home Bias & 30,416 & 0.345 & 0.000 & 0.655 \\
& & 0.012 & 0.002 & 0.012 \\
Turnover & 28,108 & 0.251 & 0.000 & 0.749 \\
& & 0.022 & 0.008 & 0.018 \\
Disposition Effect & 3,086 & 0.160 & 0.000 & 0.840 \\
& & 0.053 & 0.021 & 0.045 \\
Performance Chasing & 25,530 & 0.267 & 0.000 & 0.733 \\
& & 0.019 & 0.003 & 0.019 \\
Skewness Preference & 30,416 & 0.266 & 0.000 & 0.734 \\
& & 0.036 & 0.017 & 0.024 \\
\hline
\end{tabular}

Table 5 reports results from maximum likelihood estimation. The different investment behaviors are modeled as linear functions of observable socioeconomic variables (see Table 4 for a list of the variables included) and unobservable random effects representing additive genetic effects $(A)$, shared environmental effects $(C)$, as well as an individual-specific error $(E)$. For each estimated model, we report the variance fraction of the combined error term explained by each unobserved effect ( $A$ Share - for the additive genetic effect, $C$ Share - for common environmental effect, $E$ Share - for the individualspecific environmental effect) as well as the corresponding bootstrapped standard errors (1,000 resamples). Investment behaviors are derived from all holdings of stocks as well as equity mutual funds. All variables are defined in Appendix Table A1. $N$ provides the number of observations used in each estimation. 
Table 6

Robustness Checks

Panel A: Opposite-Sex Twins

\begin{tabular}{lcccc}
\multicolumn{1}{c}{ Model } & $N$ & A - Share & $C$ - Share & $E$ - Share \\
\hline Diversification & 7,916 & 0.379 & 0.083 & 0.538 \\
& & 0.111 & 0.084 & 0.044 \\
Home Bias & 7,916 & 0.459 & 0.013 & 0.528 \\
& & 0.086 & 0.063 & 0.041 \\
Turnover & 7,412 & 0.270 & 0.000 & 0.730 \\
& & 0.053 & 0.033 & 0.032 \\
Disposition Effect & \multirow{2}{*}{564} & 0.245 & 0.000 & 0.755 \\
& & 0.135 & 0.043 & 0.120 \\
Performance Chasing & 4,390 & 0.331 & 0.085 & 0.584 \\
& & 0.102 & 0.079 & 0.040 \\
Skewness Preference & 7,916 & 0.282 & 0.000 & 0.718 \\
& & 0.057 & 0.037 & 0.036 \\
\hline
\end{tabular}

Panel B: Model Misspecification

\begin{tabular}{lcccc}
\multicolumn{1}{c}{ Model } & $N$ & A - Share & $C$ - Share & $E$ - Share \\
\hline Home Bias & 12,378 & 0.505 & -0.044 & 0.539 \\
& & 0.102 & 0.072 & 0.042 \\
Turnover & \multirow{2}{*}{11,508} & 0.356 & -0.082 & 0.726 \\
& & 0.077 & 0.051 & 0.033 \\
Disposition Effect & \multirow{2}{*}{782} & 0.411 & -0.098 & 0.688 \\
& & 0.292 & 0.180 & 0.136 \\
Skewness Preference & \multirow{2}{*}{12,378} & 0.325 & -0.039 & 0.714 \\
& & 0.101 & 0.070 & 0.041
\end{tabular}


Table 6 (continued)

Panel C: Excluding Similar Portfolios

\begin{tabular}{lcccc}
\multicolumn{1}{c}{ Model } & $N$ & A - Share & $C$ - Share & $E$ - Share \\
\hline Diversification & 9,902 & 0.327 & 0.015 & 0.658 \\
& & 0.078 & 0.049 & 0.042 \\
Home Bias & 9,902 & 0.236 & 0.000 & 0.764 \\
Turnover & & 0.061 & 0.028 & 0.043 \\
& & 0.208 & 0.000 & 0.792 \\
Disposition Effect & \multirow{2}{*}{5890} & 0.044 & 0.021 & 0.033 \\
& & 0.155 & 0.000 & 0.845 \\
Performance Chasing & 5,208 & 0.116 & 0.048 & 0.103 \\
& & 0.201 & 0.060 & 0.739 \\
Skewness Preference & 9,902 & 0.087 & 0.060 & 0.040 \\
& & 0.111 & 0.054 & 0.835 \\
& & 0.067 & 0.051 & 0.031 \\
\hline
\end{tabular}

Panel D: Controlling for Differences in Intra-Twin Pair Communication

\begin{tabular}{lcccc}
\multicolumn{1}{c}{ Model } & $N$ & A - Share & $C$ - Share & $E$ - Share \\
\hline Diversification & 6,228 & 0.251 & 0.176 & 0.578 \\
& & $0.130-0.369$ & $0.073-0.282$ & $0.544-0.598$ \\
Home Bias & 6,228 & 0.216 & 0.209 & 0.574 \\
Turnover & & $0.130-0.360$ & $0.090-0.292$ & $0.547-0.604$ \\
& 5,836 & 0.241 & 0.020 & 0.744 \\
Disposition Effect & & $0.136-0.272$ & $0.000-0.108$ & $0.725-0.764$ \\
& 412 & 0.177 & 0.000 & 0.805 \\
Performance Chasing & & $0.000-0.297$ & $0.000-0.080$ & $0.702-0.953$ \\
& 3,544 & 0.224 & 0.164 & 0.612 \\
Skewness Preference & & $0.131-0.315$ & $0.089-0.251$ & $0.586-0.638$ \\
& 6,228 & 0.209 & 0.071 & 0.723 \\
& & $0.080-0.290$ & $0.000-0.179$ & $0.694-0.757$ \\
\hline
\end{tabular}


Table 6 (continued)

Panel E: Investors with at Least $20 \%$ of Total Assets Invested in Risky Financial Assets

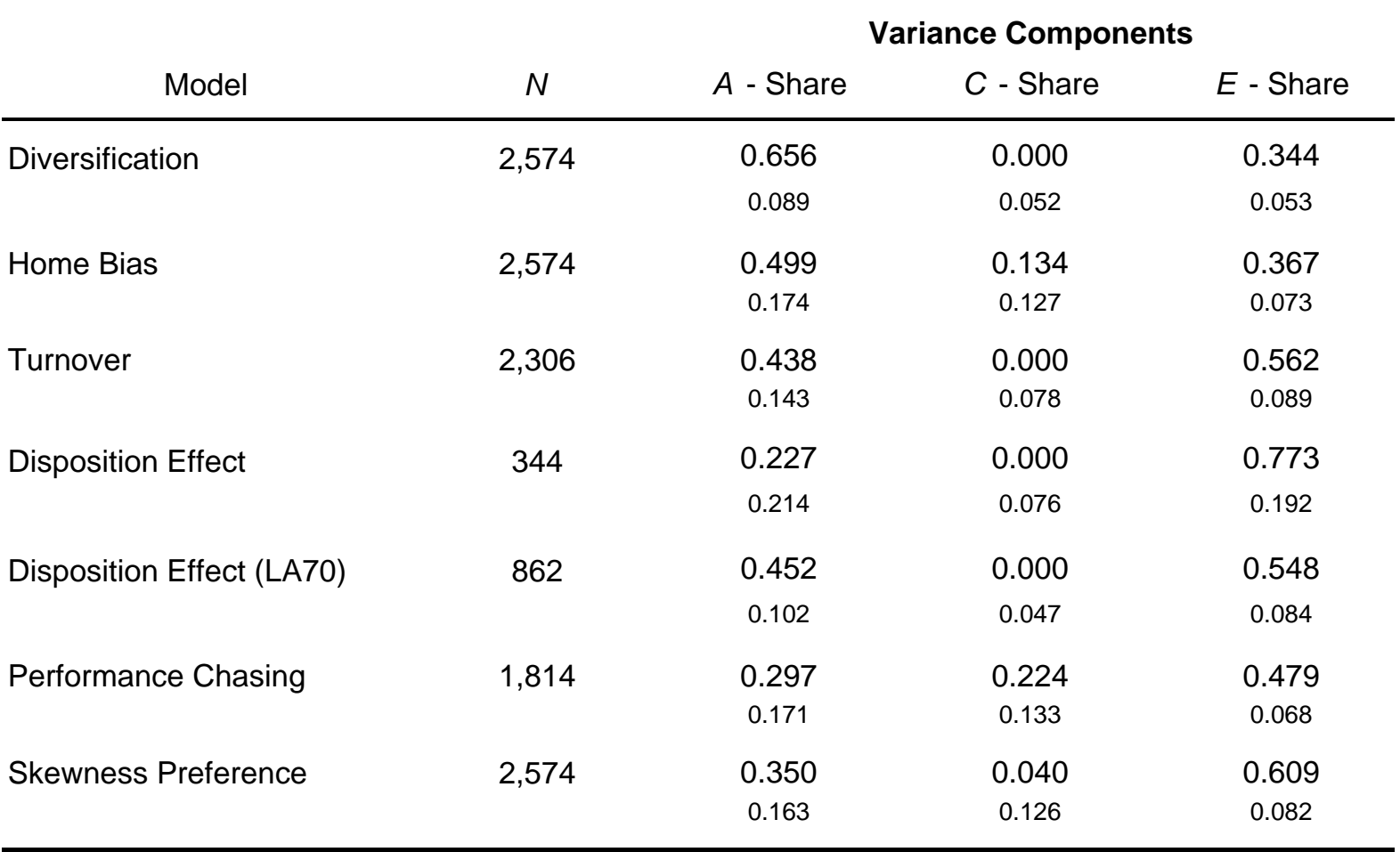

Table 6 reports results from maximum likelihood estimation for investment behaviors measured on direct stock holdings only. The different investment behaviors are modeled as linear functions of observable socioeconomic variables (see Table 4 for a list of the variables included) and unobservable random effects representing additive genetic effects $(A)$, shared environmental effects (C), as well as an individual-specific error (E). For each estimated model, we report the variance fraction of the combined error term explained by each unobserved effect ( $A$ Share - for the additive genetic effect, $C$ Share - for common environmental effect, $E$ Share - for the individual-specific environmental effect) as well as (except for Panel $D$ ) the corresponding bootstrapped standard errors (1,000 resamples). Panel A presents results for the subset of twin pairs that exclude opposite-sex twin pairs. Panel B allows the variance components to take on negative values for cases where the shared environmental component (C) is estimated to be zero in Table 4. Panel C reports results for the subset of twin pairs for whom the sum of the absolute value of portfolio weight differences is at least one (on a range between zero (identical portfolios) and two (non-overlapping portfolios). In Panel D, twin pairs are sorted into ten bins based on contact frequency between them (contact frequency ranges from zero to 360 contacts per year). By randomly dropping identical or fraternal twins, we ensure that each bin has the same number of identical and fraternal twin pairs. We repeat the random selection 100 times and report the median as well as the $5^{\text {th }}$ and $95^{\text {th }}$ percentile of the estimated variance fractions. Panel $E$ reports results for the subsample of investors who invest at least $20 \%$ of their total assets in risky financial assets. All variables are defined in Appendix Table A1. $N$ provides the number of observations used in each estimation. 
Table 7

Behavioral Consistency: Investment Biases and Behaviors in Other Domains

Model I

$\begin{array}{cc}\text { Home } & \text { Distance to } \\ \text { Bias } & \text { Birthplace }\end{array}$

Model II

$\begin{array}{cc}\text { Home } & \text { Spouse from } \\ \text { Bias } & \text { Home Region }\end{array}$

\begin{tabular}{lcccc} 
A - Share & 0.453 & 0.400 & 0.356 & 0.148 \\
& 0.059 & 0.081 & 0.111 & 0.089 \\
C - Share & 0.000 & 0.211 & 0.000 & 0.191 \\
& 0.038 & 0.056 & 0.071 & 0.066 \\
E - Share & 0.547 & 0.389 & 0.644 & 0.661 \\
& 0.036 & 0.036 & 0.073 & 0.040 \\
\hline Correlation & -0.027 & 0.003 \\
& 0.009 & 0.021 \\
Genetic Correlation & -0.101 & 0.221 \\
Correlation of Common Environment & 0.034 & 0.247 \\
Correlation of Individual Environment & 0.000 & 0.000 \\
& \multicolumn{2}{c}{0.035} & -0.073 \\
\hline$N$ & 0.021 & 0.035 \\
\hline
\end{tabular}

Table 7 reports results from maximum likelihood estimation of a bivariate models. Home Bias (measured for direct holdings of stocks) and Distance to Birthplace (Model I) or Spouse from Home Region (Model II) are modeled jointly as a linear function of observable socioeconomic characteristics (Home Bias only - see Table 4 for a list of socioeconomic variables included) as well as three unobservable random effects representing additive genetic effects $(A)$, shared environmental effects $(C)$, as well as an individual-specific error $(E)$. For each model, we report the variance fraction explained by each random effect ( $A$ Share - for the additive genetic effects, $C$ Share - for shared environmental effects, $E$ Share - for the individual-specific random effect), the overall correlation between both variables in a given model as well as the correlation between the genetic and individual specific environmental effects of each variable. Corresponding standard errors are bootstrapped with 1,000 resamples. Whenever one of the random effects $(A, C$, or $E)$ is estimated to be zero, the corresponding correlation is set to zero. All variables are defined in Appendix Table A1. $N$ provides the number of observations used in each estimation. 
Table 8

Work-related Experience with Finance

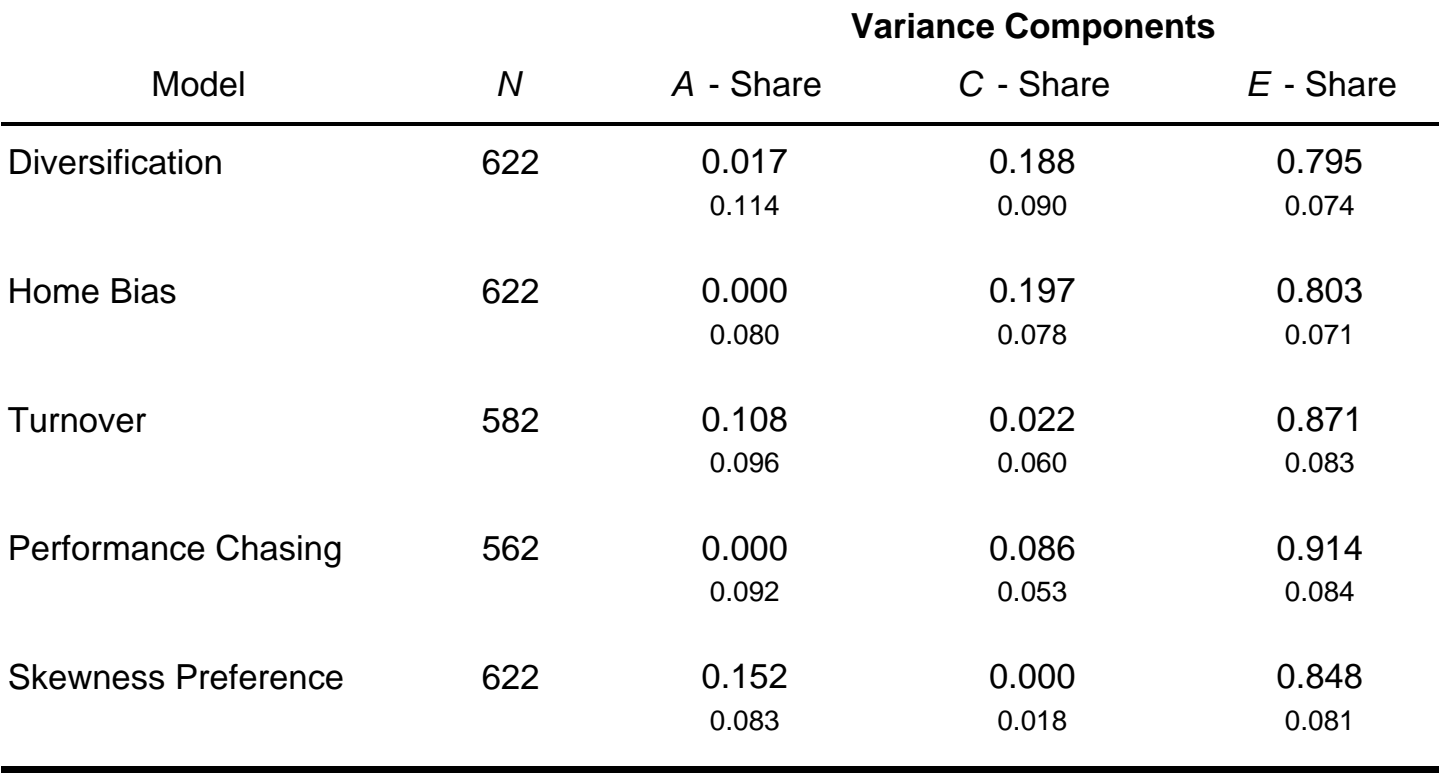

Table 8 reports results from maximum likelihood estimation for subsets of twins that have occupational experience in finance. The different investment behaviors are modeled as linear functions of observable socioeconomic variables (see Table 4 for a list of the variables included) and unobservable random effects representing additive genetic effects (A), shared environmental effects (C), as well as an individual-specific error $(E)$. The variance fraction of the combined error term explained by each unobserved effect ( $A$ Share - for the additive genetic effect, $C$ Share - for common environmental effect, $E$ Share - for the individual-specific environmental effect) as well as the corresponding bootstrapped standard errors (1,000 resamples). Investment behaviors are derived from all holdings of stocks and equity mutual funds. All variables are defined in Appendix Table A1. $N$ provides the number of observations used in each estimation. 
Table 9

Discordant Identical Twins: Investment Bias Index

\begin{tabular}{lcc} 
& Level & $\begin{array}{c}\text { Twin } \\
\text { Differences }\end{array}$ \\
\hline Intercept & 4.607 & -0.026 \\
Male & 0.626 & 0.035 \\
Age & 0.243 & \\
& 0.054 & \\
Age - squared & 0.175 & \\
High School & 0.112 & \\
College or More & 0.000 & 0.183 \\
No Education Data Available & 0.000 & 0.115 \\
& 0.017 & 0.057 \\
Married & 0.078 & 0.123 \\
Above Median Wealth Indicator & -0.307 & 0.406 \\
Log of Disposable Income & 0.074 & 0.247 \\
& -0.019 & -0.040 \\
$R^{2}$ & 0.156 & 0.067 \\
$N$ & -0.093 & -0.418 \\
& 0.054 & 0.072 \\
& -0.640 & -0.040 \\
\end{tabular}

Table 9 reports results from linear regressions of the Bias Index (column Level) and the intra twin-pair difference in the Bias Index (column Twin Difference) onto socioeconomic variables. For each estimated model, we report the coefficient estimates as well as the corresponding standard errors. Standard errors are robust to heteroscedasticity as well as correlation between twins in a twin pair. Only direct stock holdings are considered in the construction of the Bias Index. All variables are defined in Appendix Table A1. $R^{2}$ is the fraction of total variation explained by the socio-economic variables. $N$ provides the number of observations used in each estimation. 
Appendix Table A1

Definition of all Variables

Variable

Description

Types of Twins

Identical Twins

Non-identical Twins

Investment Biases \& Trading Behavior Diversification

Home Bias

Turnover

Disposition Effect

Performance Chasing

Skewness Preference
Twins that are genetically identical, also called monozygotic twins. Zygosity is determined by the Swedish Twin Registry based on questions about intrapair similarities in childhood.

Twins that share on average $50 \%$ of their genes, also called dizygotic or fraternal twins. Non-identical twins can be of the same sex or of opposite sex. Zygosity is determined by the Swedish Twin Registry based on questions about intrapair similarities in childhood.

For direct stock holdings, Diversification is defined as the number of distinct stocks held in an individual's portfolio at the end of a year. For holdings of stocks and mutual funds, Diversification is defined as the proportion invested in mutual funds, but not invested in individual stocks. To reduce measurement error, we calculate the equally weighted average Diversification across all years the individual is in the data set. Home Bias is defined as the equity portfolio share of Swedish securities.In particular, at the end of each year and for each investor, we add the market value of all Swedish stocks in the investor's portfolio to the market value of the Swedish equity allocation of all mutual funds held by the investor. We divide the value of these Swedish equity holdings by the total market value of direct (i.e. stocks) and indirect (i.e. equity allocation of mutual funds) equity holdings. We classify stocks as Swedish or foreign based on the country in which the stock is legally registered, as reflected in the country code of a given stock's ISIN. For mutual funds, we collect annual fund-specific data from Morningstar on the fund's total equity allocation as well as on the fund's equity allocation to Sweden. For equity or mixed mutual funds that are not covered by Morningstar we infer the fund's investment focus from the fund's name. By default, we assume that the fund is fully invested in international equities. Only if the fund name suggests an investment focus on Swedish equity, we classify the fund as Swedish. Finally, to improve the precision of our measure, for each investor we calculate the equally weighted average Home Bias across all years with non-missing data.

For direct stock holdings, we divide, for each individual investor and year, the sales volume (in Swedish krona) during the year by the value of directly held stocks at the beginning of the year. Since we do not have sales price information for mutual funds, we also construct a turnover measure using the number of sales during the year divided by the number of equity securities in the investor's portfolio at the beginning of the year. In each case, Turnover is defined as the average annual turnover using all years with equity holdings data for an investor. To avoid that our analysis is affected by outliers, we drop observations for which Turnover is higher than the top one percentile of the Turnover distribution.

We measure the Disposition Effect as the difference between the ratio of the number of realized to realized and unrealized gains and the ratio of the number of realized to realized and unrealized losses (see Odean (1998) and Dhar and Zhou (2006)). We do not observe purchases of securities and even though we have data on sales transactions, we do not observe the date of the transaction. We therefore use changes in the annual holding data to identify net purchases and sales of equity securities for each investor. We start by dropping all securities that are present in an investor's portfolio in 1998, the beginning of our sample period, as we cannot observe when the security entered the investor's portfolio. Next, when we observe a given security for the first time in an investor's portfolio at the end of the year, we assign the average (tax) value (averaged between the (tax) value of the previous and the current year) as the relevant purchase and reference price. We increase (decrease) this reference price when additional units of this security are purchased at a higher (lower) value in later years. At the end of each year with at least one sales transaction in the relevant group of securities (stocks or stocks and equity mutual funds), we compare the reference price of each security in an investor's portfolio (including those securities whose holdings decrease to zero over that year) to the currrent value of the security (where the current value is the average of the (tax) value of the previous and the current year). If the current value is higher (lower) than the reference price, we consider the position a gain (loss). We further categorize gains and losses as realized if the number of units held decreases relative to the previous year, and unrealized otherwise. Finally, for each investor, we count the total number of realized and unrealized gains and losses. The Disposition Effect is then the difference between the ratio of realized to realized and unrealized gains and the ratio of realized to realized and unrealized losses. It is set to missing unless both ratios exist. Performance Chasing is measured by an individual's propensity to purchase securities that have performed well in the recent past. Specifically, each year we sort stocks and equity mutual funds separately into return deciles using the raw returns during the year. For each investor and year, we calculate the fraction of purchased securities (identified by positive net-changes of annual holdings) with returns in the top two deciles. Performance Chacing is the average of this fraction over all years in which an investor has made net-purchases of securities.

Skewness Preference is measured in the spirit of Kumar (2009). For each investor and year we calculate the fraction of the portfolio that is invested in "lottery" securities. We define a security as a lottery security if it has a below median price as well as above median idiosyncratic volatility and skewness. We use a the world market return, the squared world market return, the local Swedish market return, and the squared local market returns factor in our asset pricing model to determine a security's idiosyncratic error term. Regressions are performed every year using the last 24 months of return data. Skewness Preference is the fraction of lottery securities held in an investor's equity portfolio, averaged over all years with portfolio data. 

holdings. It takes on values between zero and twelve. For each behavior, we assign a value of zero (no bias), one, or two (most biased), depending on the observed level. The index is the sum across all six investment behaviors. If for a given investor, a behavior is missing, we use the median behavior to assign the bias index component (zero, one, or two). In particular, for Diversification, we assign two to investors with only one stock, one to investors with two to six stocks, and zero to investors with more than six stocks. For Home Bias, we assign two to investors with a 100\% allocation to Swedish stocks, one to investors with less than $100 \%$, but more than $20 \%$ allocation to Swedish stocks, and zero for investors with less than $20 \%$ Swedish allocation. For Turnover, we assign two to investors with a value above $55 \%$, one to investors with a value between $20 \%$ and $55 \%$, and zero otherwise. For Disposition Effect, we assign two to investors with a disposition effect over $40 \%$, one to investors with a strictly positive disposition effect, and zero otherwise. For Performance Chasing, we assign two to investors with a value above $40 \%$, one to investors with a value between 20 and 40\%, and zero otherwise. For Skewness preference, we assign two to investors with a value above $15 \%$, one to investors with a value between 5 and $15 \%$, and zero otherwise.

Socioeconomic Characteristics Male

Age

Less than High School

High School

College or more

No Education data available

Years of Education

Married

Disposable Income

Financial Assets

Total Assets

Net Worth

Number of Stocks and Equity Mutual Funds

Value of Stocks and Equity Mutual Funds

Number of Stocks

Value of Stocks

Number of Equity Mutual Funds

Value of Equity Mutual Funds

Contact Intensity

Distance to Birthplace

Spouse from Home Region
An indicator variable that equals one if an individual is male and zero otherwise. Gender is obtained from Statistics Sweden.

The average age over the years an individual is included in our sample. Age is obtained from the Statistics Sweden.

An indicator variable that equals one if an individual has not completed high school (gymnsasium) zero otherwise. Educational information is obtained from Statistics Sweden.

An indicator variable that equals one if an individual has completed high school (gymnasium) but has not attended university, zero otherwise. Educational information is obtained from Statistics Sweden.

An indicator variable that equals one if an individual has attended university, zero otherwise. Educational information is obtained from Statistics Sweden.

An indicator variable that equals one if no educational data are available for an individual, zero otherwise. Educational information is obtained from Statistics Sweden.

Years of Education is based on the highest completed degree. For a subset of the sample, the variable is obtained from the Swedish Twin Registry. We use a linear regression model to extend the variable to the rest of our sample. Specifically, we regress the years of education onto indicator variables High School and College or More (avaialable for most individuals in our data set from Statistics Sweden) and then predict years of education out of sample.

The average (over the years an individual is included in our sample) of an annual indicator variable that equals one if an individual is married in a given year and zero otherwise. The marital status is obtained from the Statistics Sweden.

The average individual disposable income (over the years an individual is included in our sample), as defined by Statistics Sweden, that is, the sum of income from labor, business, and investment, plus received transfers, less taxes and alimony payments. Expressed in nominal Swedish Krona (SEK) (unless indicated otherwise). The data are obtained from Statistics Sweden.

The average end-of-year market value of an individual's financial assets (over the years an individual is included in our sample) as reported by Statistics Sweden, expressed in nominal Swedish Krona (SEK) (unless indicated otherwise). Financial assets include checking, savings, and money market accounts, (direct and indirect) bond holdings, (direct and indirect) equity holdings, investments in options and other financial assets such as rights, convertibles, and warrants.

The average end-of-year market value of an individual's financial and real assets (over the years an individual is included in our sample) as reported by Statistics Sweden, expressed in nominal Swedish Krona (SEK) (unless indicated otherwise)

The average difference between the end-of-year market value of an individual's assets and her liabilities (over the years an individual is included in our sample), as reported by Statistics Sweden. Expressed in nominal Swedish Krona (SEK) (unless indicated otherwise). We form indicator variables that indicate whether an individual's networth is in the first, second, third, or first quartile of the net-worth distribution. The average end-of-year number of holdings of distinct individual stocks and equity mutual funds (over the years an individual is included in our sample), as reported by Statistics Sweden.

The average end-of-year market value of holdings of individual stocks and equity mutual funds (over the years an individual is included in our sample), as reported by Statistics Sweden. Expressed in nominal Swedish Krona (SEK) (unless indicated otherwise).

The average end-of-year number of holdings of distinct individual stocks (over the years an individual is included in our sample), as reported by Statistics Sweden.

The average end-of-year market value of holdings of individual stocks (over the years an individual is included in our sample), as reported by Statistics Sweden. Expressed in nominal Swedish Krona (SEK) (unless indicated otherwise).

The average end-of-year number of holdings of distinct equity mutual funds (over the years an individual is included in our sample), as reported by Statistics Sweden.

The average end-of-year market value of holdings of equity mutual funds (over the years an individual is included in our sample), as reported by Statistics Sweden. Expressed in nominal Swedish Krona (SEK) (unless indicated otherwise).

The number of contacts per year between twins. The number is calculated as the average of the numbers reported by both twins. If only one twin provides a number, this number is used. The data are obtained from the Swedish Twin Registry.

The driving distance in kilometers to the state of birth. We define this distance to be the average distance to the center of all municipalities within the state of birth weighted by their population. The distance is obtained from Google Maps. The population numbers are obtained from Statistics Sweden.

An indicator variable available for married individuals that takes on the value of one if the spouse was born in the same state as the individual and zero otherwise. 


\section{Appendix Table A2}

Education as a Moderator

Years of

Education

Bias Index

\begin{tabular}{|c|c|c|c|}
\hline \multicolumn{2}{|c|}{ Moderator } & \multicolumn{2}{|c|}{ Investment Bias Index } \\
\hline \multirow[t]{2}{*}{$a \_m$} & 0.2300 & a_c & 0.0010 \\
\hline & 0.010 & & 0.129 \\
\hline \multirow[t]{2}{*}{$c \_m$} & -0.1300 & alpha_c & -0.0209 \\
\hline & 0.010 & & 0.112 \\
\hline \multirow[t]{20}{*}{$e \_m$} & 0.1100 & a_u & 0.3940 \\
\hline & 0.000 & & 0.121 \\
\hline & & alpha_u & 0.3483 \\
\hline & & & 0.109 \\
\hline & & $c \_c$ & -0.0950 \\
\hline & & & 0.168 \\
\hline & & chi_c & 0.2161 \\
\hline & & & 0.152 \\
\hline & & c_u & -0.0790 \\
\hline & & & 0.211 \\
\hline & & chi_u & 0.3082 \\
\hline & & & 0.192 \\
\hline & & $e \_c$ & 0.0290 \\
\hline & & & 0.060 \\
\hline & & epsilon_c & -0.0384 \\
\hline & & & 0.108 \\
\hline & & e_u & 0.9830 \\
\hline & & & 0.060 \\
\hline & & epsilon_u & 0.0774 \\
\hline & & & 0.049 \\
\hline$N$ & & 11,800 & \\
\hline
\end{tabular}

Appendix Table A2 reports parameter estimates and standard errors (s.e.) from maximum likelihood estimation of gene-environment interactions models (see Figure 2 for a presentation of the model). The moderator variable is education as measured by years of education (divided by 10 for computational reasons). The Bias Index is based on financial behaviors related to direct stock holdings only. In a first stage (untabulated), we have removed (via linear regression) the effect of control variables listed in Table 4, with the exception of those related to education. $N$ provides the number of observations. 
Figure 1

Correlations by Genetic Similarity

- Identical Twins $\quad \square$ Fraternal Twins $\quad$ Fraternal Twins - Same Sex $\quad$ Fraternal Twins - Opposite Sex

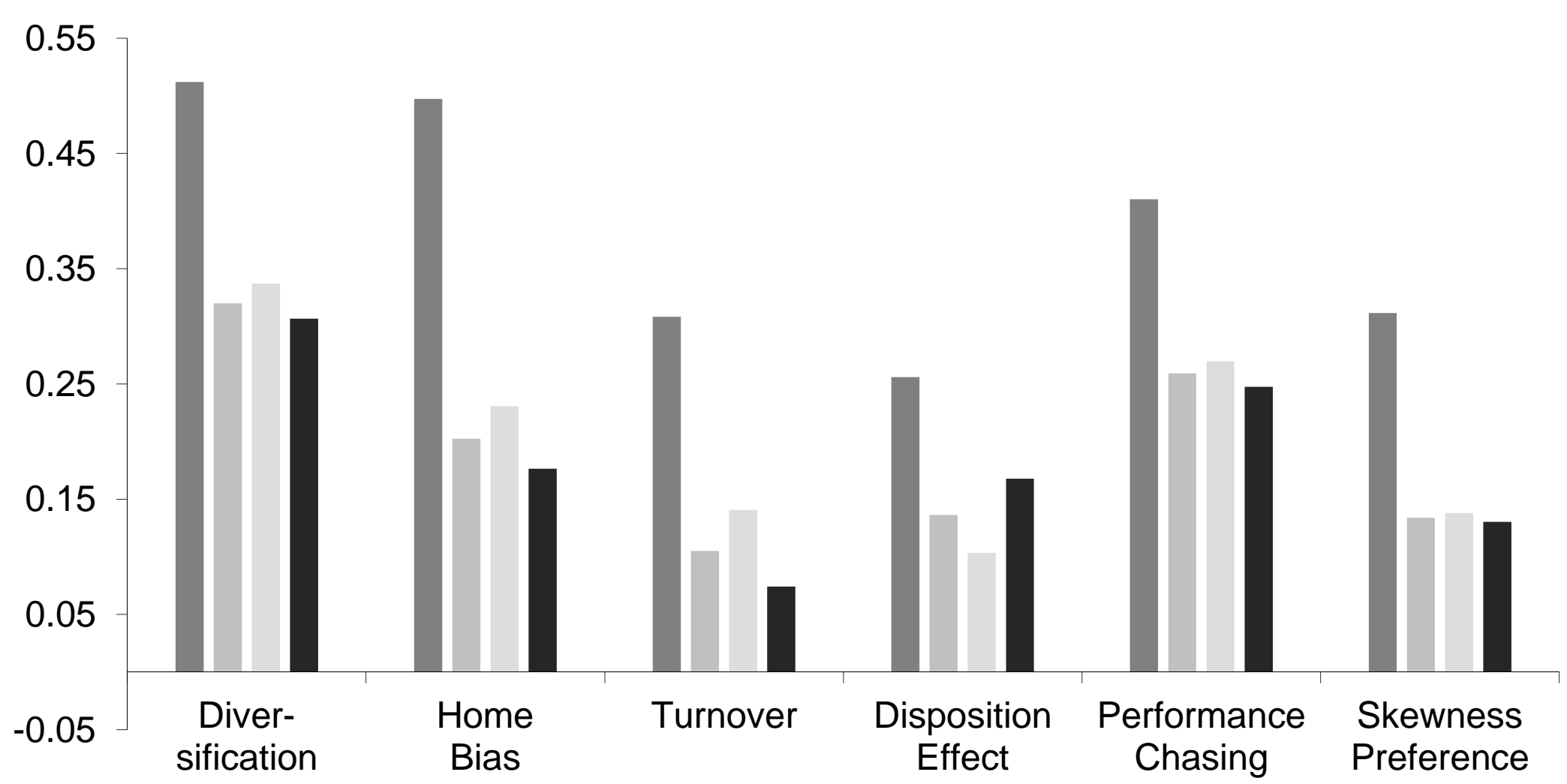

Figure 1 repots Pearson correlation coefficients for Diversification, Home Bias, Disposition Effect, Performance Chasing, and Turnover between twins for different types of twin pairs. Investment behaviors are calculated using holdings and transactions of direct stock holdings only. All variables are defined in Appendix Table A1. 
Figure 2

Gene-Environment Interaction

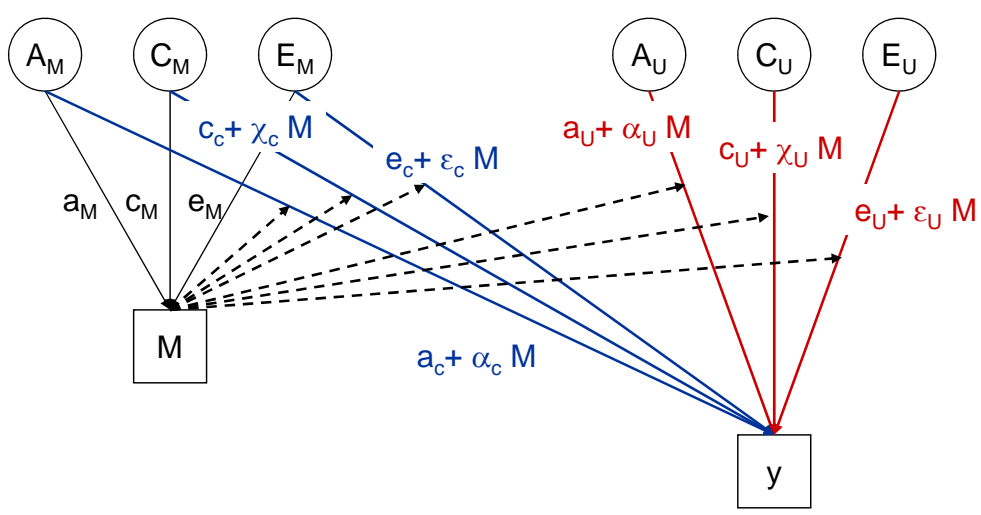

Figure 2 presents a graphical presentation of the gene-interaction model proposed by Purcell (2002). $M$ symbolizes the moderator and $y$ the Investment Bias Index. $A, C$, and $E$ correspond to the unobservable genetic and environmental factors. See Purcell (2002) for details. 


\section{Figure 3}

\section{Education as a Moderator}

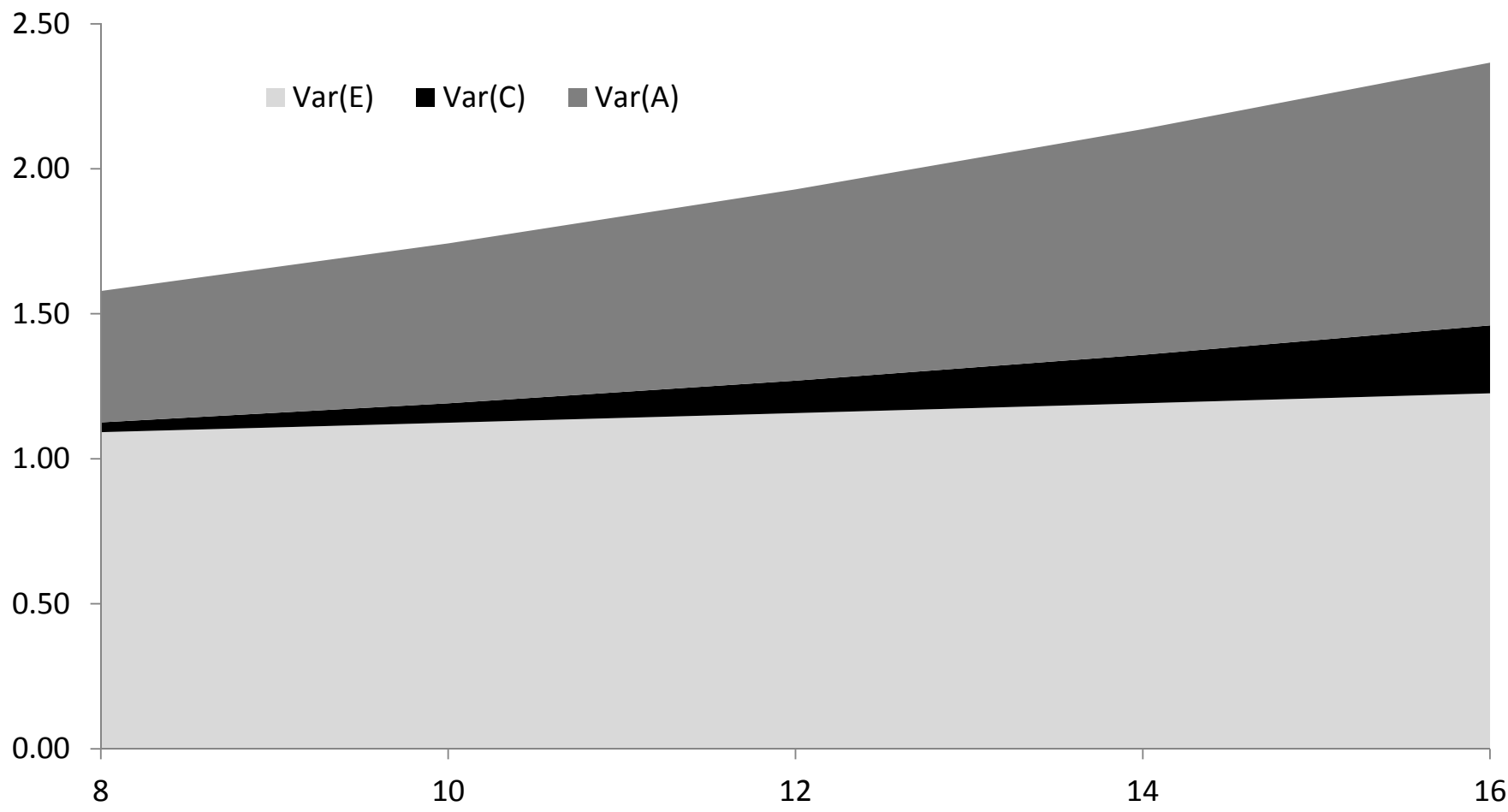

Figure 3 presents results of the gene-interaction model proposed by Purcell (2002). Years of Education acts as the environmental moderator. The $x$-axis represents years of education, while the $y$-axis represents the residual variance of the Investment Bias Index, due to genetic effects (A - blue), the common environment $(\mathrm{C}-\mathrm{red})$ and the individual-specific environment $(\mathrm{E}-$ green). See Appendix Table A2 for detailed estimation results. 